\title{
Summary Discussion of the 1996 Performance Assessment for the Waste Isolation Pilot Plant
}

\author{
J. C. Helton, ${ }^{a}$ D. R. Anderson, ${ }^{b}$ G. Basabilvazo, ${ }^{c}$ H.-N. Jow ${ }^{b}$, M. G. Marietta ${ }^{b}$ \\ a Department of Mathematics, Arizona State University, Tempe, AZ 85287 USA; b Sandia National \\ Laboratories, Albuquerque, NM 87185 USA; ${ }^{c}$ U.S. Department of Energy, Carlsbad, NM 88221 USA
}

\begin{abstract}
The Waste Isolation Pilot Plant (WIPP) is under development by the U.S. Department of Energy (DOE) for the geologic disposal of transuranic waste. The construction of complementary cumulative distribution functions (CCDFs) for total radionuclide release from the WIPP to the accessible environment is described. The resultant CCDFs (i) combine releases due to cuttings and cavings, spallings, direct brine release, and long-term transport in flowing groundwater, (ii) fall substantially to the left of the boundary line specified by the U.S. Environmental Protection Agency's (EPA's) standard 40 CFR 191 for the geologic disposal of radioactive waste, and (iii) constitute an important component of the DOE's successful Compliance Certification Application to the EPA for the WIPP. Insights and perspectives gained in the performance assessment (PA) that led to these CCDFs are described, including the importance of (i) an iterative approach to PA, (ii) uncertainty and sensitivity analysis, (iii) a clear conceptual model for the analysis, (iv) the separation of stochastic (i.e., aleatory) and subjective (i.e., epistemic) uncertainty, (v) quality assurance procedures, (vi) early involvement of peer reviewers, regulators, and stakeholders, (vii) avoidance of conservative assumptions, and (viii) adequate documentation.
\end{abstract}

Key Words: Aleatory uncertainty, complementary cumulative distribution function, compliance certification application, epistemic uncertainty, Latin hypercube sampling, Monte Carlo, performance assessment, radioactive waste, risk assessment, sensitivity analysis, stochastic uncertainty, subjective uncertainty, transuranic waste, uncertainty analysis, Waste Isolation Pilot Plant, 40 CFR 191, 40 CFR 194.

Please send page proof to:

Jon C. Helton

Department 6849, MS 0779

Sandia National Laboratories

Albuquerque, NM 87185-0779, USA

Phone: 505-284-4808

Fax: 505-844-2348

email: jchelto@sandia.gov 


\section{DISCLAIMER}

This report was prepared as an account of work sponsored by an agency of the United States Government. Neither the United States Government nor any agency thereof, nor any of their employees, make any warranty, express or implied, or assumes any legal liability or responsibility for the accuracy, completeness, or usefulness of any information, apparatus, product, or process disclosed, or represents that its use would not infringe privately owned rights. Reference herein to any specific commercial product, process, or service by trade name, trademark, manufacturer, or otherwise does not necessarily constitute or imply its endorsement, recommendation, or favoring by the United States Government or any agency thereof. The views and opinions of authors expressed herein do not necessarily state or reflect those of the United States Government or any agency thereof. 


\section{DISCLAIMER}

Portions of this document may be illegible in electronic image products. Images are produced from the best available original document. 


\section{Introduction}

The Waste Isolation Pilot Plant (WIPP) is under development by the U.S. Department of Energy (DOE) for the geologic disposal of transuranic waste. ${ }^{1-5}$ This article describes the construction of complementary cumulative distribution functions (CCDFs) for total radionuclide release from the WIPP to the accessible environment. The total release CCDFs are the primary quantitative results from the 1996 WIPP performance assessment (PA) used in determining compliance with the U.S. Environmental Protection Agency's (EPA's) standard for the geologic disposal of radioactive waste. ${ }^{6-9}$

Previous articles have discussed the construction of CCDFs for releases due to cuttings and cavings, ${ }^{10}$ spallings, ${ }^{10,11}$ direct brine release, ${ }^{12}$ and long-term radionuclide transport in flowing groundwater. ${ }^{13}$ The total release CCDFs described in this article combine the results associated with the preceding release modes into a single overall result. The resultant total release CCDFs were found to fall substantially to the left of the boundary line specified by the EPA in 40 CFR $191,{ }^{6}$ thus indicating that the WIPP is in compliance with the primary numerical standard imposed on it.

The parts of this article relating to CCDF construction are adapted from Chapt. 13 of Ref. 14. In addition, the article ends with a discussion of insights and perspectives gained in the 1996 WIPP PA.

\section{Conceptual Basis for CCDF Construction}

The 1996 WIPP PA is underlain by three entities (EN1, EN2, EN3): EN1, a probabilistic characterization of the likelihood of different futures occurring at the WIPP site over the next 10,000 yr (Sect. 3, Ref. 15); EN2, a procedure for estimating the radionuclide releases to the accessible environment associated with each of the possible futures that could occur at the WIPP site over the next 10,000 yr (Sect. 4, Ref. 15); and EN3, a probabilistic characterization of the uncertainty in the parameters used in the definitions of EN1 and EN2 (Sect. 5, Ref. 15). All three of these entities play a role in the construction of the CCDFs presented in this article.

The entity EN 1 is defined by a probability space $\left(\mathrm{S}_{s t}, \&_{s t}, p_{s t}\right)$ that characterizes stochastic (i.e., aleatory) uncertainty. Each element $\mathbf{x}_{s t}$ of the sample space $\mathrm{S}_{s t}$ corresponds to a single $10,000 \mathrm{yr}$ future at the WIPP and is given by

$$
\mathbf{x}_{s t}=[\underbrace{t_{1}, l_{1}, e_{1}, b_{1}, p_{1}, \mathbf{a}_{1}}_{1^{\text {st }} \text { intrusion }}, \underbrace{t_{2}, l_{2}, e_{2}, b_{2}, p_{2}, \mathbf{a}_{2}}_{2^{\text {nd }} \text { intrusion }}, \ldots, \underbrace{t_{n}, l_{n}, e_{n}, b_{n}, p_{n}, \mathbf{a}_{n}}_{n^{\text {th }} \text { intrusion }}, t_{\min }],
$$

where $n$ is the number of drilling intrusions, $t_{i}$ is the time (yr) of the $i^{\text {th }}$ intrusion, $l_{i}$ designates the location of the $i^{\text {th }}$ intrusion, $e_{i}$ designates the penetration of an excavated or nonexcavated area by the $i^{\text {th }}$ intrusion, $b_{i}$ designates where 
or not the $i^{\text {th }}$ intrusion penetrates pressurized brine in the Castile Formation, $p_{i}$ designates the plugging procedure used with the $i^{\text {th }}$ intrusion (i.e., continuous plug, two discrete plugs, three discrete plugs), $\mathbf{a}_{i}$ designates the type of waste penetrated by the $i^{\text {th }}$ intrusion (i.e., no waste, contact-handled (CH) waste, remotely-handled (RH) waste), and $t_{\min }$ is the time at which potash mining occurs within the land withdrawal boundary (Sect. 3, Ref. 15; Ref. 16).

The entity EN2 is defined by a function $f$ of the form

$$
\begin{aligned}
f\left(\mathbf{x}_{s t}\right)= & f_{C}\left(\mathbf{x}_{s t}\right)+f_{S P}\left[\mathbf{x}_{s t}, f_{B}\left(\mathbf{x}_{s t}\right)\right]+f_{D B R}\left\{\mathbf{x}_{s t}, f_{S P}\left[\mathbf{x}_{s t}, f_{B}\left(\mathbf{x}_{s t}\right)\right], f_{B}\left(\mathbf{x}_{s t}\right)\right\} \\
& +f_{M B}\left[\mathbf{x}_{s t}, f_{B}\left(\mathbf{x}_{s t}\right)\right]+f_{D L}\left[\mathbf{x}_{s t}, f_{B}\left(\mathbf{x}_{s t}\right)\right]+f_{S}\left[\mathbf{x}_{s t}, f_{B}\left(\mathbf{x}_{s t}\right)\right] \\
& +f_{S-T}\left\{\mathbf{x}_{s t, 0}, f_{S-F}\left(\mathbf{x}_{s t, 0}\right), f_{N-P}\left[\mathbf{x}_{s t}, f_{B}\left(\mathbf{x}_{s t}\right)\right]\right\}
\end{aligned}
$$

where $\mathbf{x}_{s t} \sim$ particular future under consideration, $\mathbf{x}_{s t, 0} \sim$ future involving no drilling intrusions but a mining event at the same time $t_{\min }$ as in $\mathbf{x}_{s t}, f_{C}\left(\mathbf{x}_{s t}\right) \sim$ cuttings and cavings release to accessible environment for $\mathbf{x}_{s t}$ calculated with CUTTINGS_S, $f_{B}\left(\mathbf{x}_{s t}\right) \sim$ two-phase flow results calculated for $\mathbf{x}_{s t}$ with BRAGFLO (in practice, $f_{B}\left(\mathbf{x}_{s t}\right)$ is a vector containing a large amount of information), $f_{S P}\left[\mathbf{x}_{s t}, f_{B}\left(\mathbf{x}_{s t}\right)\right] \sim$ spallings release to accessible environment for $\mathbf{x}_{s t}$ calculated with the spallings model contained in CUTTINGS_S (this calculation requires BRAGFLO results (i.e., $\left.f_{B}\left(\mathbf{x}_{s t}\right)\right)$ as input), $f_{D B R}\left\{\mathbf{x}_{s t}, f_{S P}\left[\mathbf{x}_{s t}, f_{B}\left(\mathbf{x}_{s t}\right)\right], f_{B}\left(\mathbf{x}_{s t}\right)\right\} \sim$ direct brine release to accessible environment for $\mathbf{x}_{s t}$ calculated with a modified version of BRAGFLO designated BRAGFLO_DBR (this calculation requires spallings results obtained from CUTTINGS_S (i.e., $f_{S P}\left[\mathbf{x}_{s t}, f_{B}\left(\mathbf{x}_{s t}\right)\right]$ ) and BRAGFLO results (i.e., $f_{B}\left(\mathbf{x}_{s t}\right)$ ) as input), $f_{M B}\left[\mathbf{x}_{s t}, f_{B}\left(\mathbf{x}_{s t}\right)\right] \sim$ release through anhydrite marker beds to accessible environment for $\mathbf{x}_{s t}$ calculated with NUTS (this calculation requires BRAGFLO results (i.e., $f_{B}\left(\mathbf{x}_{s t}\right)$ ) as input), $f_{D L}\left[\mathbf{x}_{s t}, f_{B}\left(\mathbf{x}_{s t}\right)\right] \sim$ release through Dewey Lake Red Beds to accessible environment for $\mathbf{x}_{s t}$ calculated with NUTS (this calculation requires BRAGFLO results (i.e., $\left.f_{B}\left(\mathbf{x}_{s t}\right)\right)$ as input), $f_{S}\left[\mathbf{x}_{s t}, f_{B}\left(\mathbf{x}_{s t}\right)\right] \sim$ release to land surface due to brine flow up a plugged borehole for $\mathbf{x}_{s t}$ calculated with NUTS or PANEL (this calculation requires BRAGFLO results (i.e., $\left.f_{B}\left(\mathbf{x}_{s t}\right)\right)$ as input), $f_{S-F}\left(\mathbf{x}_{s t, 0}\right) \sim$ Culebra flow field calculated for $\mathbf{x}_{s t, 0}$ with SECOFL2D, $f_{N-P}\left[\mathbf{x}_{s t}, f_{B}\left(\mathbf{x}_{s t}\right)\right] \sim$ release to Culebra for $\mathbf{x}_{s t}$ calculated with NUTS or PANEL as appropriate (this calculation requires BRAGFLO results (i.e., $f_{B}\left(\mathbf{x}_{s t}\right)$ ) as input), $f_{S-T}\left\{\mathbf{x}_{s t, 0}, f_{S-F}\left(\mathbf{x}_{s t, 0}\right), f_{N-P}\left[\mathbf{x}_{s t}, f_{B}\left(\mathbf{x}_{s t}\right)\right]\right\} \sim$ groundwater transport release through Culebra to accessible environment calculated with SECOTP2D (this calculation requires SECOFL2D results (i.e., $f_{S-F}\left(\mathbf{x}_{s t, 0}\right)$ ) and NUTS or PANEL results (i.e., $\left.f_{N-P}\left[\mathbf{x}_{s t}, f_{B}\left(\mathbf{x}_{s t}\right)\right]\right)$ as input; $\mathbf{x}_{s t, 0}$ is used as an argument to $f_{S-T}$ because drilling intrusions are assumed to cause no perturbations to the flow field in the Culebra) (Sect. 4, Ref. 15; Refs. 10-13, 17, 18). 
Of the functions appearing in Eq. (2), only $f_{C}, f_{D B R}$ and $f_{S P}$ produced nonzero results in the 1996 WIPP PA. ${ }^{10}$, 12, 13. Thus, in this PA, $f$ can be viewed as a function of the form

$$
f\left(\mathbf{x}_{s t}\right)=f_{C}\left(\mathbf{x}_{s t}\right)+f_{S P}\left[\mathbf{x}_{s t}, f_{B}\left(\mathbf{x}_{s t}\right)\right]+f_{D B R}\left\{\mathbf{x}_{s t}, f_{S P}\left[\mathbf{x}_{s t}, f_{B}\left(\mathbf{x}_{s t}\right)\right], f_{B}\left(\mathbf{x}_{s t}\right)\right\}
$$

for the determination of total release to the accessible environment. The specific procedures used to obtain $f_{C}, f_{S P}$ and $f_{D B R}$ in the 1996 WIPP PA are described in Sect. 5 of Ref. 10, Sect. 10 of Ref. 10, and Sect. 11 of Ref. 12, respectively.

Determination of the CCDF for total radionuclide release to the accessible environment involves evaluation of the following integral (Sect. 4, Ref. 15):

$$
\operatorname{prob}_{f}(\operatorname{Rel}>R)=\int_{S_{s t}} \delta_{R}\left[f\left(\mathbf{x}_{s t}\right)\right] d_{s t}\left(\mathbf{x}_{s t}\right) d V_{s t}
$$

where $\delta_{R}\left[f\left(\mathbf{x}_{s t}\right)\right]=1$ if $f\left(\mathbf{x}_{s t}\right)>R$ and 0 if $f\left(\mathbf{x}_{s t}\right) \leq R, d_{s t}$ is the density function associated with the probability space $\left(\mathrm{S}_{s t}, \&_{s t}, p_{s t}\right)$ for stochastic uncertainty (Sect. 3, Ref. 15; Ref. 16), and $\operatorname{prob}_{f}(\operatorname{Rel}>R$ ) is the probability that a normalized release (Eq. (1), Ref. 15) greater than size $R$ will occur. In practice, the preceding integral is too complex to allow a closed-form evaluation. As a result, the 1996 WIPP PA uses the Monte Carlo procedure indicated below to estimate this integral (Sect. 4, Ref. 15; Sects. 10, 11, Ref. 16):

$$
\operatorname{prob}_{f}(\operatorname{Rel}>R)=\sum_{i=1}^{n S} \delta_{R}\left[f\left(\mathbf{x}_{s t, i}\right)\right] / n S
$$

where the $\mathbf{x}_{s t, i}, i=1,2, \ldots, n S=10,000$, correspond to a random sample of size $n S=10,000$ from the sample space $\mathrm{S}_{s t}$ associated with the probability space $\left(\mathrm{S}_{s t}, \& \quad s t, p_{s t}\right)$ for stochastic uncertainty.

The entity EN3 is defined by a probability space $\left(\mathrm{S}_{s u}, \&_{s u}, p_{s u}\right)$ that characterizes subjective (i.e., epistemic) uncertainty (Sect. 5, Ref. 15; Ref. 19). Each element $\mathbf{x}_{s u}$ of the sample space $\mathrm{S}_{s u}$ corresponds to a single set of values for the $n V$ uncertain variables considered in the analysis and has the form

$$
\mathbf{x}_{s u}=\left[x_{1}, x_{2}, \ldots, x_{n V}\right]
$$

where each $x_{i}$ is an uncertain input and $n V=57$ in the 1996 WIPP PA (Table 1, Ref. 19).

When the effects of imprecisely known analysis inputs are included, the representations for $f$ and its component functions in Eqs. (2) - (5) will also contain a dependence on $\mathbf{x}_{s u}$. The possible values for $\mathbf{x}_{s u}$ lead to distributions of release results for specific futures $\mathbf{x}_{s t}$ and also for the CCDFs that result from integrating over all possible values for 
$\mathbf{x}_{s t}$ In the 1996 WIPP PA, these distributions are approximated by using Latin hypercube sampling 20 to generate a mapping from $\mathrm{S}_{s u}$ to analysis outcomes of interest (Sect. 5, Ref. 15; Sect. 8, Ref. 19). The generation and presentation of this mapping is usually referred to as uncertainty analysis. Once generated, this mapping can be explored with sensitivity analysis techniques based on examination of scatterplots, regression analysis, and correlation analysis (Sect. 3.5, Ref. 21).

\section{Total Release: CCDFs}

The CCDFs for total release were constructed with release values of the form indicated in Eq. (3). Further, this construction was carried out for each sample element associated with 3 replicated Latin hypercube samples (LHSs) of size 100 (Sect. 8, Ref. 19). Specifically, the analysis involved $3 \times 100=300$ LHS elements and resulted in 300 $\mathrm{CCDF}$ for total release to the accessible environment.

The outcome is a distribution of CCDFs that falls substantially below the limit specified in 40 CFR 191 (Fig. 1). The dominant contributor to total release is cuttings removal (i.e., $f_{C}$ ) (Fig. 6, Ref. 10); a substantial contribution is also made by spallings (i.e., $f_{S P}$ ) for some LHS elements (Fig. 16, Ref. 10). Direct brine release (i.e., $f_{D B R}$ ) is a small, and often zero, contributor to the total release (Fig. 16, Ref. 12). The appearance of the 90th quantile substantially below and to the left of the boundary line specified in 40 CFR 191 is indicative of a high confidence that the WIPP does indeed meet this regulation (Fig. 1).

The three replicated LHSs (Sect. 8, Ref. 19) provide a check on the stability of the results in Fig. 1 (Fig. 2). Reassuringly, the estimated mean and quantiles are quite stable across the three replicates, and a tight confidence interval is obtained for the mean. Similar stability was also observed for the cuttings (Fig. 7, Ref. 10), spallings (Fig. 17, Ref. 10) and direct brine release (Fig. 17, Ref. 12) CCDFs.

The CCDFs for total release can be reduced to expected values (Fig. 3). Comparison of expected values for cuttings, spallings, direct brine release and total release shows that the total release is dominated by cuttings. For a few LHS elements, the release to the Culebra exceeds the total release due to cuttings, spallings and direct brine release. However, these releases were not transported through the Culebra to the accessible environment. ${ }^{13}$

\section{Total Release: Sensitivity Analysis}

Stepwise regression analysis with rank-transformed data (Sect. 3.5, Ref. 21; Ref. 22) can be used to determine the dominant contributors to the expected value for total release due to cuttings, spallings and direct brine release (Table 1). The two dominant variables with respect to uncertainty in the expected total release are WMICDFLG (microbial gas generation flag) and WTAUFAIL (waste shear strength) (see Table 1, Ref. 19, for more information on the definition and use of WMICDFLG, WTAUFAIL and other variables), with the size of the expected release tending 
to increase as WMICDFLG increases and tending to decrease as WTAUFAIL increases. The positive effect for WMICDFLG results from its influence on the size of the spallings release (Table 4, Fig. 19, Ref. ${ }^{10}$ ), and the negative effect for WTAUFAIL results from its influence on the size of the cuttings release (Eq. (32), Fig. 8, Ref. 10). As a reminder, the total release is dominated by spallings and cuttings (Fig. 3), with WMICDFLG and WTAUFAIL being the dominant contributors to the uncertainty in these two release modes. The remaining seven variables in the regression model (i.e., WGRCOR, WPRTDIAM, HALPOR, BHPRM, HALPRM, WASTWICK, ANHPRM; see Table 1 , Ref. 19, for variable descriptions) appear primarily because of their effects on the spallings release. Indeed, these are exactly the same seven variables selected after WMICDFLG in the regression analysis for spallings releases (Table 4, Ref. 10). A discussion of the effects of these variables is provided in conjunction with Table 4 of Ref. 10.

For perspective, scatterplots involving WMICDFLG, WTAUFAIL, WPRTDIAM (waste particle diameter) and $B H P R M$ (borehole permeability) are presented in Fig. 4. The tendency of the expected release to increase with increasing values for WMICDFLG and to decrease with increasing values for WPRTDIAM can be seen in the corresponding scatterplots. The scatterplot for WTAUFAIL clearly shows the interplay of the spallings and cuttings components of the total release. The scatterplot is bounded below by points that correspond to LHS elements in which the cuttings release is much larger than the spallings release (see Fig. 8 of Ref. 10 for the corresponding scatterplot for cuttings releases only); LHS elements in which spallings is a significant contributor to the total release produce points above this lower curve. The scatterplots for WPRTDIAM and BHPRM show a tendency for the largest releases to be associated with small values for WPRTDIAM and BHPRM, with these associations resulting from the effects of WPRTDIAM and BHPRM on the size of the spallings release (see Sect. 10, Ref. 10).

As for spallings (Fig. 20, Ref. 10), an alternative investigation of the effects of uncertainty on the CCDFs in Fig. 1 is provided by partial rank correlation coefficients (PRCCs) (Fig. 5; see Sect. 3.5, Ref. 21). Specifically, the probability of exceeding a given release tends to go up as WMICDFLG increases and tends to go down as WTAUFAIL increases. The basis of these effects is discussed in conjunction with Table 1, with WMICDFLG and WTAUFAIL being the first two variables selected in the stepwise regression analysis summarized in Table 1.

\section{Discussion}

For the 1996 WIPP PA, the total release CCDF fell substantially to the left of the EPA boundary (Fig. 1). This was the case even when the uncertainties present in the analysis were incorporated into the determination of this CCDF. Further, the numerical integration procedure based on Latin hypercube sampling that led to the estimate of a distribution of CCDFs due to subjective uncertainty and a mean CCDF over subjective uncertainty was shown to be quite stable (Fig. 2). These results constituted the core component of a Compliance Certification Application $(C C A)^{23}$ by the DOE to the EPA for the certification of the WIPP for the disposal of transuranic waste (see pp. XWALK-1 to XWALK-36, Ref. 23 , for a complete description of the regulatory requirements placed on the WIPP 
by the EPA and how these requirements were met in the CCA). After extensive review of the CCA, the EPA certified the WIPP for the disposal of transuranic waste in May 1998. ${ }^{24}$ As a result, the WIPP is the first operational facility in the United States for the geologic disposal of radioactive waste.

The certification of the WIPP for radioactive waste disposal was the culmination of a long development process. Various insights and perspectives that emerged from this process are now presented.

\subsection{Evolution of WIPP PA}

The 1996 WIPP PA has its origins in the extended search in the United States for an acceptable disposal procedure for radioactive waste. ${ }^{1-5}$ Immediate precursors to the development of a PA capability for the WIPP are several large projects at Sandia National Laboratories (SNL) that involved analyses of nuclear power reactors or radioactive waste disposal concepts. These projects supplied both ideas and personnel that contributed to the development of a PA capability for the WIPP. These programs include a U.S. Nuclear Regulatory Commission (NRC) project to develop a PA methodology for the geologic disposal of high-level radioactive waste, ${ }^{25-28}$ an international program to study the subseabed disposal of radioactive waste, ${ }^{29}$ and the NRC's reassessment of the risk from commercial nuclear power plants. 30,31

A PA capability for the WIPP was developed through a sequence of PAs, with individual PAs carried out in $1989,{ }^{32,} 331990,{ }^{34} 1991,{ }^{35}$ and $1992 .{ }^{36}$ An overview of the computational procedures used in these PAs is given by Rechard, ${ }^{37}$ and summaries of the 1991 and 1992 PAs are available in the journal literature. ${ }^{38-40}$ Further, a specialized approach to PA designated the System Prioritization Methodology (SPM) was developed and tested in the 1994-1995 time frame. ${ }^{41-46}$

In general, these PAs tended to follow a progression from simple and exploratory to complex and focused as the sophistication of the models and the analysis strategy for the use of these models increased and as the regulatory requirements that would be placed on the WIPP became better defined. The iterative and evolutionary nature of the PA process for the WIPP contributed to the development of a final PA (i.e., the 1996 PA) that was focused on regulatory issues of importance, well-understood, computationally practicable, and free of serious errors. Maintenance of organizational and personnel continuity contributed significantly to the implementation of a sequence of iterative PAs and the use of the resultant knowledge and insights.

The 1996 WIPP PA involves many interacting components that are discussed in various articles in this special issue of Reliability Engineering \& System Safety. Included in these components are descriptions of the natural and engineered systems that define the WIPP and its environment, ${ }^{47-50}$ regulatory requirements, ${ }^{9}$ a features, events and processes (FEPs) screening procedure, ${ }^{51}$ experimental programs and associated data, ${ }^{2,48}$ models and their associated computational implementation, ${ }^{2}, 10-13,17,18,48$ a conceptual structure for the overall PA, ${ }^{15}, 16,19$ procedures for 
uncertainty and sensitivity analysis, ${ }^{19,21}$ a computational strategy for assembling the complete PA, ${ }^{10}, 12,13,15,16,18$, 19 computational resources necessary to carry out and archivally store the calculations that underlie the $\mathbf{P A}, 52$ and appropriate quality assurance (QA) procedures. ${ }^{53}$ None of these components remained fixed over the approximately 10 yr period (i.e., 1987-1996) during which the WIPP PA capability evolved. Rather, they all changed as insights were gained about the WIPP and on how to conduct a PA for the WIPP.

Uncertainty and sensitivity analysis played an important role in helping to guide the development of the WIPP, $35,36,54,55$ with many of the individual studies published in the journal literature. ${ }^{38-40,56-58}$ Uncertainty and sensitivity analysis helped (i) identify the areas in which the greatest benefit could be derived from the reduction of uncertainty through improved models or data, (ii) identify computational strategies that could increase the numerical efficiency of the PA, (iii) enhance credibility of analyses by providing a representation of the uncertainty in predictions of interest, and (iv) contributed to QA by providing an extensive examination of analysis results. Extensive uncertainty and sensitivity studies have been carried out as part of the 1996 WIPP PA. ${ }^{10,12-14,18,59-61}$ These studies contributed to the 1996 WIPP PA by providing a representation of the uncertainty in analysis outcomes and a strong indication that the numerical implementation of the analysis was operating correctly, with the preceding helping to enhance confidence that the WIPP does indeed satisfy applicable regulations.

Regulatory requirements had a significant effect on the development of a PA capability for the WIPP.2, 9,15 Initially, the regulatory status of the WIPP was unclear. However, after the promulgation of 40 CFR $191^{6}$ by the EPA in 1985, the WIPP project used this regulation for guidance. ${ }^{62,63}$ With the passage of the Land Withdrawal Act (LWA) ${ }^{64}$ in 1992, 40 CFR 191 was established as the regulation pertaining to radioactive waste disposal at the WIPP, and the EPA was specified as the regulator with authority to certify compliance with 40 CFR 191. As mandated in the LWA, the EPA published an elaboration of the intent of 40 CFR 191 and specific procedures to be used in assessing compliance with 40 CFR 191 in 40 CFR $194 .{ }^{8}$ The EPA repromulgated 40 CFR 191 in 1993 but with no changes that affected PA for the WIPP. ${ }^{7}$ Together, 40 CFR 191 and 40 CFR 194 mandated a full PA for the WIPP, including separation of the effects of stochastic (i.e., aleatory) and subjective (i.e., epistemic) uncertainty. Due to extensive interactions between the EPA and the PA staff at Sandia, the mandated PA process was similar in concept to the PA processes for the WIPP that had been evolving at Sandia since the late 1980s. ${ }^{62,63}$ Additional discussion is provided in Sect. 5.2.

Outside review was a significant component in the development of a PA capability for the WIPP. Prior to the 1996 WIPP PA, outside review was provided by a National Academy of Science (NAS) review committee which typically met four times a year with members of the WIPP project and issued periodic reports (e.g., Refs. 4, 65, 66), the New Mexico Environmental Evaluation Group (EEG) which provided independent review of the WIPP project for the State of New Mexico (e.g., Refs. 67-70), and a Performance Assessment Review Committee that met several times a year from 1988 to 1993 with members of the PA team to review work in this area. The review process was facilitated by extensive publication of WIPP-related work in technical reports (e.g., Refs. 14, 32-37), conference 
proceedings (e.g., Refs. 71, 72, 73), and the journal literature (e.g., Refs. 38-40). Subsequent to the 1996 WIPP PA, review continued to be provided by the NAS review committee and the EEG (e.g., Refs. 74-76). Further, additional review was provided by a Conceptual Models Peer Review Group, ${ }^{77}$ an International Review Group, ${ }^{78}$ several specially impaneled review groups, ${ }^{79-83}$ and the EPA. Publication of WIPP-related work, including this special issue of Reliability Engineering \& System Safety, continues to provide an opportunity for a broad-based review of the 1996 WIPP PA.

Stakeholder involvement was actively encouraged in the development of the WIPP. The involvement of the EEG certainly constituted one form of stakeholder involvement. Outside the formal involvements of the EEG, the most active stakeholder group constituted the community of Carlsbad. ${ }^{5}$ This group felt that the development of the WIPP would have a positive impact on their community and formed a constituency that strongly supported the WIPP. The WIPP project benefited from this group of positive and active stakeholders. In contrast to other contentious projects such as the development of the Yucca Mountain disposal facility for high-level radioactive waste, there was relatively little opposition to the development of the WIPP (see Ref. 5 for a detailed discussion of the political environment within which the WIPP was developed).

A PA is a procedure for assembling information from many sources. Extensive experimental programs were carried out in support of PA for the WIPP. 2, 3, 48 As it became available, information emerging from these programs was incorporated into PA for the WIPP. As a result, PAs for the WIPP tended to be better supported by experimental results as they developed from 1989 to 1996.

\subsection{Regulatory Involvement}

In the early stages of the development of the WIPP, the DOE was self-regulating. Thus, there was no outside regulator and no outside regulations to be considered in the development of the WIPP. However, with the promulgation of 40 CFR 191 by the EPA in 1985, the WIPP project used this regulation for guidance in the development of a PA capability. ${ }^{62,63}$ With the passage of the LWA and the resultant promulgation of 40 CFR 194, specific regulatory requirements deriving from 40 CFR 191 were placed on the WIPP. These requirements led to a well-defined conceptual structure for the 1996 WIPP PA $^{15}$ and a computational strategy for carrying out calculations in the context of this structure. ${ }^{10,12,13,16,18,19}$

Prior to the CCA, EPA staff met extensively with the WIPP PA team to develop a high-level understanding of the nature of the calculations intended for use in the 1996 WIPP PA and thus for use in support of the CCA. As the 1996 WIPP PA developed, EPA staff carried out an ongoing review of the data, models, computer programs and computational structure intended for use in this analysis. This review required a significant commitment of time and qualified personnel by the EPA. However, it greatly facilitated later review of the CCA and justification of the 
EPA's certification decision by providing EPA staff who understood the 1996 WIPP PA and its use in support of the CCA.

The EPA carried out an extensive review of the CCA and the PA calculations that supported it. As part of this review, additional PA calculations were performed at SNL under the guidance of EPA staff. ${ }^{84}$ Further, as previously indicated, additional outside review by two specially convened committees was also carried out. ${ }^{77,78}$ The outcome of the CCA and the EPA's associated review was a certification decision in May 1998. ${ }^{24}$ The first receipt of waste at the WIPP took place on March 26, 1999.

As mandated in 40 CFR 194, the WIPP must undergo recertification every five years beginning at first receipt of waste (i.e., March 1999, implying a required recertification by March 2004). If required by the EPA, this recertification will be supported by a PA similar to the 1996 WIPP PA used in support of the CCA. This PA will provide a means to incorporate any improved data, models and insights that have been developed since the CCA. For example, it is anticipated that future PAs in support of recertification and/or changes in the design of the WIPP will include improved models for spallings and direct brine releases. ${ }^{11,85}$

Although not considered in this special issue of Reliability Engineering \& System Safety, the WIPP was also required to obtain a permit from the State of New Mexico for the disposal of hazardous (i.e., nonradioactive) wastes as mandated by the Resource Conservation and Recovery Act (RCRA). ${ }^{86}$ This permit was issued in October 1999. ${ }^{87}$ Only nonmixed waste (i.e., waste without hazardous components regulated by RCRA) was emplaced in the WIPP prior to the issuance of the RCRA permit.

\subsection{Iterative Nature of PA}

Performance assessment should be an iterative process. Initially, PA can be primarily exploratory and relatively simple. Early PA efforts provide opportunities for (i) uncertainty and sensitivity analysis, (ii) development of insights with respect to the systems under study, (iii) outside review, (iv) regulator and stakeholder involvement, (v) initiation of a QA program, and (vi) education of analysis participants on what to expect in later analyses. From such efforts, guidance emerges on (i) experimental programs and data development, (ii) model development, including the appropriateness of more or less complex models, and (iii) computational structure for a fully integrated analysis.

Intermediate PAs are typically more complex than initial PAs. At times, intermediate PAs are pushed towards unnecessary complexity or complexity that exceeds available data by model developers or outside reviewers. However, PAs tend to improve through multiple iterations as (i) more data becomes available or increased understanding improves the match between available data and model requirements, (ii) the appropriateness and implementation of individual models improves, (iii) the design and assembly of the entire PA improves due to increased understanding of both the overall system and results obtained from individual models, and (iv) the benefits 
of an appropriately implemented QA program are realized. In addition, continued iterations provide opportunities for (i) review of alternative models, (ii) uncertainty and sensitivity analyses, (iii) identification of errors in analysis or model implementation, and (iv) continued education of analysis participants, regulators, and stakeholders.

The final PA (e.g., the PA supporting the CCA in the case of the WIPP) benefits from the experiences of the prior analyses, including (i) a well-defined and well-tested analysis system that will produce no surprises in the final analysis, (ii) an analysis focused on recognized needs and requirements, (iii) use of models appropriate for the requirements of the analysis, including use of simplified models when prior analyses have indicated that this is acceptable due to either analysis requirements or resolution in available data, (iv) QA procedures emplaced and employed with models and an analysis system that have been previously used and tested, and (v) analysts, reviewers, regulators and stakeholders who are familiar with the analysis due to prior involvement.

\subsection{Conservative Assumptions}

The idea of a conservative assumption is often encountered in PAs for radioactive waste disposal and other complex facilities. In the context of PA, conservative is used in the designation of an assumption or analysis approach that will lead to results that are more unfavorable in some sense than the analysts involved believe they should be. Put another way, a conservative assumption is an assumption that is believed to lead to less favorable analysis outcomes than should really be the case. As used here, the designation conservative does not apply to assumptions that are made for analysis convenience but are not intended to shift analysis results in an unfavorable manner (e.g., using a permeability of zero rather than a very low nonzero permeability).

Conservative assumptions are widely warned against (e.g., Sect. 6, Ref. 15; Ref. 88) and should be avoided. Analyses based on conservative assumptions often produce misleading results and provide an inadequate basis for informed decisions. By their very nature, conservative assumptions lead to analysis results that are believed to be incorrect. The dangers of conservative assumptions are particularly evident when decisions must be made about the allocation of resources among several alternatives (e.g., which experimental programs to support to reduce the uncertainty in an analysis outcome of interest). When an analysis employs conservative assumptions, decisions on such allocations cannot be made in a meaningful manner.

A compounding difficulty is that conservative assumptions can be difficult to make for a least two reasons. First, what constitutes a conservative assumption in a complex analysis is not always easy to determine. In particular, an assumption that is believed to be conservative for one process can be nonconservative for another process. In the 1996 WIPP PA as an example, a high borehole permeability is conservative for long-term radionuclide transport from the repository to the Culebra Dolomite but nonconservative for radionuclide release to the surface environment due to spallings and direct brine release. Second, the standardization of the meaning of conservative over multiple analysts is very difficult. Often, the extremeness of conservative assumptions can vary 
widely from individual to individual. Sometimes, realistic conservative assumptions are asked for but, unfortunately, the preceding phrase is an oxymoron.

Rather than employing conservative assumptions, an analysis should strive to be honest about the amount of uncertainty present in its assumptions and hence in analysis results. In particular, the goal of a well-designed and executed analysis should be results that are neither deliberately pessimistic nor deliberately optimistic. Further, such results should be accompanied by a fair representation of the uncertainty that is present. In designing such an analysis, it is often necessary to draw a distinction between uncertainty that results from inherent variability associated with the system under study (i.e., stochastic or aleatory uncertainty) and uncertainty that results from quantities that are assumed to have fixed values in the context of a particular analysis (i.e., subjective or epistemic uncertainty) ${ }^{89-94}$ Often, an expert review process must be used to assemble information from multiple sources into a useable characterization of subjective uncertainty. $95-103$

A widely expressed concern is that analysts will deliberately skew the results of a PA by using assumptions that are excessively favorable and thus will lead to analysis outcomes that are overly benign. The authors' observations are that the opposite is typically the case. When confronted with the need to deal with a poorly known analysis assumption, the ingrained tendency in many PA analysts is to make what is believed to be a conservative assumption. As a result, implementation of a nonconservative PA and determination of realistic uncertainty estimates requires significant care, effort and education. Otherwise, the PA is likely to produce misleading results due to the incorporation of a large number of assumptions of varying degrees of conservatism.

\subsection{Final Observations}

Successful implementation of a large PA requires a clear conceptual model for the overall analysis. This model then provides a basis for the design, calculation and presentation of analysis results. For the 1996 WIPP PA, this model was based on maintaining a clear separation of stochastic and subjective uncertainty and conceptually viewing the analysis as a large integration problem based on Monte Carlo procedures. ${ }^{15}$ All parts of the PA could then be viewed as specific components within this overall conceptual and computational framework.

In designing a large PA, it is important to identify exactly what the purpose of the analysis is and then focus the design on that purpose. Without such focus, a PA can easily become a large mass of isolated calculations rather than an organized effort directed to a specific purpose. For the 1996 WIPP PA, the guiding purpose defining the organization of the analysis was assessing compliance with the EPA certification criteria embodied in 40 CFR 191

and 40 CFR 194.9,15 Simply put, it is necessary to recognize clearly what the question is before an analysis can be designed and implemented to answer that question. 
Large projects such as the development of the WIPP often have separate teams of individuals responsible for experimental programs and the development of a PA capability. The two teams should be integrated from the beginning of the project so that the experimentalists will be aware of the data needs of the PA analysts, and the PA analysts will be aware of the type of information that they can reasonably expect to receive to support their work. The interaction between experimentalists and PA analysts in the conduct of periodic uncertainty and sensitivity analyses provides an effective way to achieve this integration. Such analyses require the experimentalists to provide a careful assessment of how their data supports the needs of PA and also require the PA analysts to demonstrate exactly how they intend to use the information that is being generated by the experimentalists. The subsequent examination of uncertainty and sensitivity analysis results by both groups facilitates a team approach to PA, enhances understanding of the analysis as a whole, and provides guidance for future experimental work and model development. This process probably should have been more extensive than it was in the early development of a PA capability for the WIPP, but by the 1996 WIPP PA extensive interactions between experimentalists and PA analysts were taking place in order to provide the parameter quantifications and uncertainty assessments required to support this analysis. ${ }^{19}$

Early involvement of the regulator is important in a PA carried out to support a regulatory decision. This involvement helps the PA by clarifying what the regulator desires and helps the regulator by providing advance perspectives and knowledge on what will be incorporated into the PA and how the PA will support the regulatory application. The WIPP PA was fortunate to have an early, active and insightful involvement with the EPA before the completion of the 1996 WIPP PA in support of the CCA of the same year.

Involvement with a regulator is only one aspect of the review that a large PA should undergo. Extensive review from multiple sources is important and should be considered an integral part of any large PA. Such review provides valuable feedback to a PA on the appropriateness of analysis assumptions, enhances the credibility of a PA by making it clear that the PA process is open to review, comment and criticism, and develops a knowledgeable group of individuals outside the organization implementing the PA that can be called on for informed commentary on the PA. As described earlier, the WIPP PA actively participated in, and devoted significant resources to, extensive outside review.

A PA should avoid the use of conservative assumptions. Simply put, how can a PA be a PA if it is based on conservative assumptions? On the whole, the 1996 WIPP PA attempted to avoid the use of conservative assumptions but be forthright about the uncertainty present in the analysis. Such a goal is always imperfectly achieved in a large analysis. In particular, it is difficult to eliminate the tendency of many individuals to make what they believe to be conservative assumptions when confronted with substantial uncertainty. Further, some analysis assumptions may be mandated by regulation and thus are not open to review as part of a PA (e.g., the conservative requirement in 40 CFR 194 that the drilling rate for deep resources observed in the Delaware Basin for the last 100 yr be assumed to continue unchanged for the next $10,000 \mathrm{yr}$ ). In review subsequent to completion of the 1996 WIPP 
PA, it was decided that the spallings model probably overestimated the size of the spallings release and thus provided conservative release results. ${ }^{11,85}$

Carrying out a PA for a complex system such as the WIPP is a large undertaking. Development of a conceptual structure for the PA, models for use within this structure, and numerical procedures for carrying out the PA are important parts of this undertaking. Three additional components that should be carefully addressed in a PA are (i) appropriate management and archival storage of calculations, (ii) QA, and (iii) documentation.

The total calculations that must be carried out and stored in a large PA such as the 1996 WIPP can be massive. For the 1996 WIPP PA, a designated group of individuals was given sole responsibility for conducting and storing all calculations. ${ }^{52}$ This freed the individual PA analysts from this responsibility and assured that all calculations were carried out and archivally stored in a traceable manner.

Appropriate QA procedures are essential parts of a large PA to assure both the PA team and individuals outside the team (e.g., peer reviewers, regulators, stakeholders) that the analysis has been properly carried out. This is particularly true of PAs that support regulatory decisions. Such PAs must be supported by some type of documented and verifiable QA process. Without a suitable QA process, it is difficult to ensure traceability and reproducibility for the analysis and thereby to enhance confidence that the results of the analysis are correct and should be accepted as a reasonable representation of the behavior of the system under study. The 1996 WIPP PA was supported by an extensive QA process. ${ }^{53}$

Although QA procedures are an important part of a large analysis, such procedures must be appropriately designed and implemented. In particular, an excessively restrictive set of QA procedures can use up unnecessarily large amounts of project resources, stifle innovative and efficient solution of problems, and, in the end, actually damage rather than enhance the quality of the analysis. In practice, some type of graded QA process is needed whereby the QA effort expended on individual activities can be adjusted to take into account the potential effects that these activities will have on the final results of the PA. For example, exploratory analyses performed early in the PA process require less QA than a final PA that will be used in comparisons with a regulatory standard. Although not sufficient by itself, the most important component of assuring quality in a large analysis is a group of analysts who feel a strong personal and professional identification with the work that they are doing.

Documentation is an important part of a PA. Documentation typically must be carried out on several levels. Clearly, documentation is an important part of any QA process, but QA documentation is not very useful for obtaining an overview of a PA and the models used within the PA. Thus, documentation is needed that describes the models in use, the data that supports these models, the computer programs and numerical procedures in use, and the overall structure of the PA. The 1996 WIPP PA produced extensive documentation, including analysis packages (e.g., Refs. 104-111), data reports (e.g., Refs. 112-117), users' manuals for computer programs (e.g., Refs. 118-127), 
descriptions of analysis structure and uncertainty/sensitivity analyses, ${ }^{14}$ QA results (e.g., see the parts of Refs. 104111 that relate to adherence to QA procedures), review reports (e.g., Refs. 80-86), and the CCA itself. ${ }^{23}$ A major component of the 1996 WIPP PA and associated CCA was the production of adequate documentation. Indeed, this special issue of Reliability Engineering \& System Safety is intended to be the most publicly accessible part of the documentation for the 1996 WIPP PA. Most PAs underestimate the time, effort and resources required to produce adequate documentation.

The geologic disposal of radioactive waste is a topic of wide interest and some controversy (e.g., Refs. 1, 128139). Adhering to the analysis properties indicated above helped contribute to the success of the 1996 WIPP PA and ultimately to the positive certification decision for the WIPP. It is hoped that others who are interested in radioactive waste disposal will find the 1996 WIPP PA and the perspectives derived from it both interesting and useful.

\section{Acknowledgment}

Work performed for Sandia National Laboratories (SNL), which is a multiprogram laboratory operated by Sandia Corporation, a Lockheed Martin Company, for the United States Department of Energy under contract DE-AC04-94AL85000. Review provided at SNL by M. Chavez, C. Crawford and M.S. Tierney. Editorial support provided by L. Harrison, T. Allen, and H. Radke of Tech Reps, Inc.

\section{References}

1. Rechard, R.P. 1999. "Historical Relationship Between Performance Assessment for Radioactive Waste Disposal and Other Types of Risk Assessment," Risk Analysis. Vol. 19, no. 5, pp. 763-807.

2. Rechard, R.P., Historical Background on Performance Assessment for the Waste Isolation Pilot Plant, Reliability Engineering and System Safety (in this issue).

3. Rechard, R.P. 1999. Historical Background on Assessing the Performance of the Waste Isolation Pilot Plant. SAND98-2708. Albuquerque, NM: Sandia National Laboratories.

4. National Academy of Sciences/National Research Council. 1996. The Waste Isolation Pilot Plant, A Potential Solution for the Disposal of Transuranic Waste. Washington DC: National Academy Press.

5. Mora, C.J. 1999. Sandia and the Waste Isolation Pilot Plant 1974 - 1999. SAND99-1482. Albuquerque, NM: Sandia National Laboratories.

6. U.S. Environmental Protection Agency. 1985. "Environmental Standards for the Management and Disposal of Spent Nuclear Fuel, High-Level and Transuranic Radioactive Wastes; Final Rule, 40 CFR Part 191," Federal Register. Vol. 50, pp. 38066-38089. 
7. U.S. Environmental Protection Agency. 1993. "40 CFR Part 191: Environmental Radiation Protection Standards for the Management and Disposal of Spent Nuclear Fuel, High-Level and Transuranic Radioactive Wastes; Final Rule, Federal Register,58, 66398-66416.

8. U.S. Environmental Protection Agency. 1996. "40 CFR Part 194: Criteria for the Certification and ReCertification of the Waste Isolation Pilot Plant's Compliance With the 40 CFR Part 191 Disposal Regulations; Final Rule," Federal Register, 61 (28) 5224-5245.

9. Howard, B.A., M.B. Crawford, D.A. Galson, and M.G. Marietta, Regulatory Basis for the Waste Isolation Pilot Plant Performance Assessment, Reliability Engineering and System Safety (in this issue).

10. Berglund, J.W., J.W. Garner, J.C. Helton, J.D. Johnson, and L.N. Smith, Direct Releases to the Surface and Associated Complementary Cumulative Distribution Functions in the 1996 Performance Assessment for the Waste Isolation Pilot Plant: Cuttings, Cavings and Spallings, Reliability Engineering and System Safety (in this issue).

11. Knowles, M.K., F.D. Hansen, T.W. Thompson, M.B. Gross, and J.F. Schatz, Review and Perspectives on Spallings Releases in the 1996 Performance Assessment for the Waste Isolation Pilot Plant, Reliability Engineering and System Safety (in this issue).

12. Stoelzel, D.M., D.G. O'Brien, J.W. Garner, J.C. Helton, J.D. Johnson, and L.N. Smith, Direct Releases to the Surface and Associated Complementary Cumulative Distribution Functions in the 1996 Performance Assessment for the Waste Isolation Pilot Plant: Direct Brine Release," Reliability Engineering and System Safety (in this issue).

13. Ramsey, J.L., R. Blaine, J.W. Garner, J.C. Helton, J.D. Johnson, L.N. Smith, and M. Wallace, Radionuclide and Colloid Transport in the Culebra Dolomite and Associated Complementary Cumulative Distribution Functions in the 1996 Performance Assessment for the Waste Isolation Pilot Plant," Reliability Engineering and System Safety (in this issue).

14. Helton, J.C., J.E. Bean, J.W. Berglund, F.J. Davis, K. Economy, J.W. Garner, J.D. Johnson, R.J. MacKinnon, J. Miller, D.G. O'Brien, J.L. Ramsey, J.D. Schreiber, A. Shinta, L.N. Smith, D.M. Stoelzel, C. Stockman, and P. Vaughn. 1998. Uncertainty and Sensitivity Analysis Results Obtained in the 1996 Performance Assessment for the Waste Isolation Pilot Plant. SAND98-0365. Albuquerque, NM: Sandia National Laboratories.

15. Helton, J.C., D.R. Anderson, G. Basabilvazo, H.-N. Jow, and M.G. Marietta, Conceptual Structure of the 1996 Performance Assessment for the Waste Isolation Pilot Plant," Reliability Engineering and System Safety (in this issue).

16. Helton, J.C., F.J. Davis, and J.D. Johnson., Characterization of Stochastic Uncertainty in the 1996 Performance Assessment for the Waste Isolation Pilot Plant, Reliability Engineering and System Safety (in this issue).

17. Vaughn, P., J.E. Bean, J.C. Helton, M.E. Lord, R.J. MacKinnon, and J.D. Schreiber, Representation of Two-Phase Flow in the Vicinity of the Repository in the 1996 Performance Assessment for the Waste Isolation Pilot Plant, Reliability Engineering and System Safety (in this issue). 
18. Stockman, C.T., J.W. Garner, J.C. Helton, J.D. Johnson, A. Shinta, and L.N. Smith, Radionuclide Transport in the Vicinity of the Repository and Associated Complementary Cumulative Distribution Functions in the 1996 Performance Assessment for the Waste Isolation Pilot Plant," Reliability Engineering and System Safety (in this issue).

19. Helton, J.C., M.-A. Martell, and M.S. Tierney, Characterization of Subjective Uncertainty in the 1996 Performance Assessment for the Waste Isolation Pilot Plant, Reliability Engineering and System Safety (in this issue).

20. McKay, M.D., R.J. Beckman, and W.J. Conover. 1979. "A Comparison of Three Methods for Selecting Values of Input Variables in the Analysis of Output from a Computer Code," Technometrics. Vol. 21, no. 2, pp. 239-245.

21. Helton, J.C. 1993. "Uncertainty and Sensitivity Analysis Techniques for Use in Performance Assessment for Radioactive Waste Disposal," Reliability Engineering \& System Safety. Vol. 42, no. 2-3, pp. 327-367.

22. Iman, R.L. and W.J. Conover. 1979. "The Use of the Rank Transform in Regression," Technometrics. Vol. 21, no. 4, pp. 499-509.

23. U.S. Department of Energy. 1996. Title 40 CFR Part 191 Compliance Certification Application for the Waste Isolation Pilot Plant. DOE/CAO-1996-2184, Volumes I-XXI, Carlsbad, NM: U.S. Department of Energy, Carlsbad Area Office.

24. U.S. Environmental Protection Agency. 1998. "Criteria for the Certification and Re-Certification of the Waste Isolation Pilot Plant's Compliance with the Disposal Regulations: Certification Decision; Final Rule," Federal Register. Vol. 63, pp. 27353-27406.

25. Campbell, J.E., R.T. Dillon, M.S. Tierney, H.T. Davis, P.E. McGrath, F.J., Jr., Pearson, H.R. Shaw, J.C. Helton, and F.A. Donath. 1978. Risk Methodology for Geologic Disposal of Radioactive Waste: Interim Report. SAND78-0029, NUREG/CR-0458. Albuquerque, NM: Sandia National Laboratories.

26. Iman, R.L., J.C. Helton, and J.E. Campbell. 1978. Risk Methodology for Geologic Disposal of Radioactive Waste: Sensitivity Analysis Techniques. SAND78-0912, NUREG/CR-0390. Albuquerque, NM: Sandia National Laboratories.

27. Cranwell, R.M., J.E. Campbell, J.C. Helton, R.L. Iman, D.E. Longsine, N.R. Ortiz, G.E. Runkle, and M.J. Shortencarier. 1987. Risk Methodology for Geologic Disposal of Radioactive Waste: Final Report. SAND81-2573, NUREG/CR-2452. Albuquerque, NM: Sandia National Laboratories.

28. Cranwell, R.M., R.V. Guzowski, J.E. Campbell, and N.R. Ortiz. 1990. Risk Methodology for Geologic Disposal of Radioactive Waste: Scenario Selection Procedure. SAND80-1429, NUREG/CR-1667. Albuquerque, NM: Sandia National Laboratories.

29. Nuclear Energy Agency. 1988. Feasibility of Disposal of High-Level Radioactive Waste into the Seabed. Paris: Organization for Economic Cooperation and Development. 
30. U.S. Nuclear Regulatory Commission. 1990-1991. Severe Accident Risks: An Assessment for Five U.S. Nuclear Power Plants. NUREG-1150, Volumes 1-3, Washington DC: U.S. Nuclear Regulatory Commission, Office of Nuclear Regulatory Research, Division of Systems Research.

31. Breeding, R.J., J.C. Helton, E.D. Gorham, and F.T. Harper. 1992. "Summary Description of the Methods Used in the Probabilistic Risk Assessments for NUREG-1150," Nuclear Engineering and Design. Vol. 135 , no. 1, pp. 1-27.

32. Lappin, A.R., R.L. Hunter, D.P. Garber, and P.B. Davies, eds.. 1989. Systems Analysis, Long-Term Radionuclide Transport, and Dose Assessments, Waste Isolation Pilot Plant (WIPP), Southeastern New Mexico; March 1989. SAND89-0462. Albuquerque, NM: Sandia National Laboratories.

33. Marietta, M.G., S.G. Bertram-Howery, D.R. Anderson, K.F. Brinster, R.V. Guzowski, H. Iuzzolino, and R.P. Rechard. 1989. Performance Assessment Methodology Demonstration: Methodology Development for Evaluating Compliance With EPA 40 CFR 191, Subpart B, for the Waste Isolation Pilot Plant. SAND89-2027. Albuquerque, NM: Sandia National Laboratories.

34. Bertram-Howery, S.G., M.G. Marietta, R.P. Rechard, P.N. Swift, D.R. Anderson, B.L. Baker, J.E. Bean, Jr., W. Beyeler, K.F. Brinster, R.V. Guzowski, J.C. Helton, R.D. McCurley, D.K. Rudeen, J.D. Schreiber, and P. Vaughn. 1990. Preliminary Comparison with 40 CFR Part 191, Subpart B for the Waste Isolation Pilot Plant, December 1990. SAND90-2347. Albuquerque, NM: Sandia National Laboratories.

35. WIPP PA (Performance Assessment). 1991-1992. Preliminary Comparison with 40 CFR Part 191, Subpart B for the Waste Isolation Pilot Plant, December 1991. SAND91-0893/1-4, Volumes 1-4, Sandia National Laboratories, Albuquerque, NM, 1991-1992.

36. WIPP PA (Performance Assessment), Preliminary Performance Assessment for the Waste Isolation Pilot Plant, December 1992. SAND92-0700/1-5, Volumes 1-5, Sandia National Laboratories, Albuquerque, NM, 1992-1993.

37. Rechard, R.P. 1995. An Introduction to the Mechanics of Performance Assessment Using Examples of Calculations Done for the Waste Isolation Pilot Plant Between 1990 and 1992. SAND93-1378. Albuquerque, NM: Sandia National Laboratories.

38. Helton, J.C., J.W. Garner, M.G. Marietta, R.P. Rechard, D.K. Rudeen, and P.N. Swift. 1993. "Uncertainty and Sensitivity Analysis Results Obtained in a Preliminary Performance Assessment for the Waste Isolation Pilot Plant," Nuclear Science and Engineering. Vol. 114, no. 4, pp. 286-331.

39. Helton, J.C., D.R. Anderson, B.L. Baker, J.E. Bean, J.W. Berglund, W. Beyeler, J.W. Garner, H.J. Iuzzolino, M.G. Marietta, R.P. Rechard, P.J. Roache, D.K. Rudeen, J.D. Schreiber, P.N. Swift, M.S. Tierney, and P. Vaughn. 1995. "Effect of Alternative Conceptual Models in a Preliminary Performance Assessment for the Waste Isolation Pilot Plant," Nuclear Engineering and Design. Vol. 154, no. 3, pp. 251-344.

40. Helton, J.C., D.R. Anderson, B.L. Baker, J.E. Bean, J.W. Berglund, W. Beyeler, K. Economy, J.W. Garner, S.C. Hora, H.J. Iuzzolino, P. Knupp, M.G. Marietta, J. Rath, R.P. Rechard, P.J. Roache, D.K. Rudeen, K. Salari, J.D. Schreiber, P.N. Swift, M.S. Tierney, and P. Vaughn. 1996. "Uncertainty and Sensitivity Analysis Results Obtained in the 1992 Performance Assessment for the Waste Isolation Pilot Plant," Reliability Engineering and System Safety. Vol. 51, no. 1, pp. 53-100. 
41. Helton, J.C., D.R. Anderson, B.L. Baker, J.E. Bean, J.W. Berglund, W. Beyeler, R. Blaine, K. Economy, J.W. Garner, S.C. Hora, R.C. Lincoln, M.G. Marietta, F.T. Mendenhall, N.H. Prindle, D.K. Rudeen, J.D. Schreiber, A.W. Shiver, L.N. Smith, P.N. Swift, and P. Vaughn. 1996. Computational Implementation of a Systems Prioritization Methodology for the Waste Isolation Pilot Plant: A Preliminary Example. SAND94-3069. Albuquerque, NM: Sandia National Laboratories.

42. Helton, J.C., W. Beyeler, and S.C. Hora. 1997. "Conceptual Basis of a Systems Prioritization Methodology for the Waste Isolation Pilot Plant," Reliability Engineering and System Safety. Vol. 57, no. 3, pp. 203-222.

43. Helton, J.C., D.R. Anderson, B.L. Baker, J.E. Bean, J.W. Berglund, W. Beyeler, R. Blaine, K. Economy, J.W. Garner, S.C. Hora, R.C. Lincoln, M.G. Marietta, F.T. Mendenhall, N.H. Prindle, D.K. Rudeen, J.D. Schreiber, A.W. Shiver, L.N. Smith, P.N. Swift, and P. Vaughn. 1997. "Computational Implementation of a Systems Prioritizatioin Methodology for the Waste Isolation Pilot Plant: A Preliminary Example," Reliability Engineering and System Safety. Vol. 57, no. 3, pp. 223-266.

44. Prindle, N.H., F.T. Mendenhall, D.M. Boak, W. Beyeler, D. Rudeen, R.C. Lincoln, K. Trauth, D.R. Anderson, M.G. Marietta, and J.C. Helton. 1996. The Second Iteration of the Systems Prioritization Method: A Systems Prioritization and Decision-Aiding Tool for the Waste Isolation Pilot Plant. Volume I: Synopsis of Method and Results. SAND95-2017/1. Albuquerque, NM: Sandia National Laboratories.

45. Prindle, N.H., F.T. Mendenhall, W. Beyeler, K. Trauth, S. Hora, D. Rudeen, and D.M. Boak. 1996. The Second Iteration of the Systems Prioritization Method: A Systems Prioritization and Decision-Aiding Tool for the Waste Isolation Pilot Plant. Volume II: Summary of Technical Input and Model Implementation. SAND95-2017/2. Albuquerque, NM: Sandia National Laboratories.

46. Prindle, N.H., D.M. Boak, R.F. Weiner, W. Beyeler, S. Hora, M.G. Marietta, J.C. Helton, D. Rudeen, H. Jow, and M. Tierney. 1996. The Second Iteration of the Systems Prioritization Method: A Systems Prioritization and Decision-Aiding Tool for the Waste Isolation Pilot Plant. Volume III: Analysis for Final Programmatic Recommendations. SAND95-2017/3. Albuquerque, NM: Sandia National Laboratories.

47. Swift, P.N. and T.F. Corbet, The Geologic and Hydrogeologic Setting of the Waste Isolation Pilot Plant, Reliability Engineering and System Safety (in this issue).

48. Larson, K.W, Development of the Conceptual Models for Chemical Conditions and Hydrology Used in the 1996 Performance Assessment for the Waste Isolation Pilot Plant, Reliability Engineering and System Safety (in this issue).

49. Hansen, F.D. and M.K. Knowles, Design and Analysis of a Shaft Seal System for the Waste Isolation Pilot Plant, Reliability Engineering and System Safety (in this issue).

50. Sanchez, L., P.E. Drez, and J.S. Rath, Radioactive and Nonradioactive Waste Intended for Disposal at the Waste Isolation Pilot Plant, Reliability Engineering and System Safety (i $\mathrm{n}$ this issue).

51. Galson, D.A., P.N. Swift, D.R. Anderson, D.G. Bennett, M.B. Crawford, T.W. Hicks, and R.D. Wilmot, Scenario Development for the Waste Isolation Pilot Plant Compliance Certification Application, Reliability Engineering and System Safety (in this issue). 
52. Froelich, G.K., C.M. Williamson, and H.C. Ogden, Computational Environment and Software Configuration Management of the 1996 Performance Assessment for the Waste Isolation Pilot Plant, Reliability Engineering and System Safety (i $\mathbf{n}$ this issue).

53. Froelich, G.K., H.C. Ogden, and K.A. Byle, Software Quality Assurance in the 1996 Performance Assessment for the Waste Isolation Pilot Plant, Reliability Engineering and System Safety (in this issue).

54. Helton, J.C., J.W. Garner, R.D. McCurley, and D.K. Rudeen. 1991. Sensitivity Analysis Techniques and Results for Performance Assessment at the Waste Isolation Pilot Plant. SAND90-7103. Albuquerque, NM: Sandia National Laboratories.

55. Helton, J.C., J.E. Bean, B.M. Butcher, J.W. Garner, J.D. Schreiber, P.N. Swift, and P. Vaughn. 1993. Uncertainty and Sensitivity Analyses for Gas and Brine Migration at the Waste Isolation Pilot Plant, May 1992. SAND92-2013. Albuquerque, NM: Sandia National Laboratories.

56. Helton, J.C., J.E. Bean, B.M. Butcher, J.W. Garner, J.D. Schreiber, P.N. Swift, and P. Vaughn. 1996. "Uncertainty and Sensitivity Analysis for Gas and Brine Migration at the Waste Isolation Pilot Plant: Fully Consolidated Shaft," Nuclear Science and Engineering. Vol. 122, pp. 1-31.

57. Helton, J.C., J.E. Bean, B.M. Butcher, J.W. Garner, J.D. Schreiber, P.N. Swift, and P. Vaughn, Uncertainty and Sensitivity Analysis for Gas and Brine Migration at the Waste Isolation Pilot Plant: Permeable Shaft with Panel Seals, Journal of Hazardous Materials, 45(2-3), 107-139, 1996.

58. Helton, J.C., J.E. Bean, B.M. Butcher, J.W. Garner, J.D. Schreiber, P.N. Swift, and P. Vaughn. Uncertainty and Sensitivity Analysis for Gas and Brine Migration at the Waste Isolation Pilot Plant: Permeable Shaft without Panel Seals, Reliability Engineering and System Safety, 57(3), 299-316, 1997.

59. Helton, J.C., J.E. Bean, K. Economy, J.W. Garner, R.J. MacKinnon, J. Miller, J.D. Schreiber, and P. Vaughn, Uncertainty and Sensitivity Analysis for Two-Phase Flow in the Vicinity of the Repository in the 1996 Performance Assessment for the Waste Isolation Pilot Plant: Undisturbed Conditions, Reliability Engineering and System Safety (this issue).

60. Helton, J.C., J.E. Bean, K. Economy, J.W. Garner, R.J. MacKinnon, J. Miller, J.D. Schreiber, and P. Vaughn, Uncertainty and Sensitivity Analysis for Two-Phase Flow in the Vicinity of the Repository in the 1996 Performance Assessment for the Waste Isolation Pilot Plant: Disturbed Conditions, Reliability Engineering and System Safety (this issue).

61. Helton, J.C., J.D. Johnson, H.-N. Jow, R.D. McCurley, and L.J. Rahal. 1998. "Stochastic and Subjective Uncertainty in the Assessment of Radiation Exposure at the Waste Isolation Pilot Plant," Human and Ecological Risk Assessment. Vol. 4, no. 2, pp. 469-526.

62. Helton, J.C. 1993. "Risk, Uncertainty in Risk, and the EPA Release Limits for Radioactive Waste Disposal," Nuclear Technology. Vol. 101, no. 1, pp. 18-39.

63. Helton, J.C., D.R. Anderson, M.G. Marietta, and R.P. Rechard. 1997. "Performance Assessment for the Waste Isolation Pilot Plant: From Regulation to Calculation for 40 CFR 191.13," Operations Research. Vol. 45 , no. 2, pp. 157-177. 
64. Public Law 102-579. 1992. Waste Isolation Pilot Plant Land Withdrawal Act. (106 Stat 4777).

65. National Academy of Sciences/National Research Council. 1984. Review of the Scientific and Technical Criteria for the Waste Isolation Pilot Plant (WIPP). Washington, DC: National Academy Press.

66. National Academy of Sciences/National Research Council. 1992. A Letter Report by the Panel on the Waste Isolation Pilot Plant, Board on Radioactive Waste Management. Washington DC: Commission on Geosciences, Environment, and Resources, National Research Council.

67. Silva, M.K. 1994. Implications of the Presence of Petroleum Resources on the Integrity of the WIPP. Albuquerque, NM: Environmental Evaluation Group.

68. Lee, W.W.-L., L. Chaturvedi, M.K. Silva, R. Weiner, and N. R.H. 1994. An Appraisal of the 1992 Preliminary Performance Assessment for the Waste Isolation Pilot Plant. Albuquerque, NM: Environmental Evaluation Group.

69. Lee, W.W.-L. 1997. "A Critical Evaluation of the 1992 Performance Assessment for the Waste Isolation Pilot Plant," Nuclear Engineering and Design. Vol. 168, no. 1-3, pp. 325-338.

70. Helton, J.C. and K.M. Trauth. 1997. "Comments on an Evaluation of the 1992 Performance Assessment for the Waste isolation Pilot Plant," Nuclear Engineering and Design. Vol. 168, no. 1-3, pp. 339-360.

71. Anderson, D.R., J.C. Helton, H.-N. Jow, and M.G. Marietta. 1996. "Performance Assessment for the Waste Isolation Pilot Plant," Probabilistic Safety Assessment and Management '96: ESREL '96-PSAM-III. Vol. 2, pp. 788-794. Eds. C. Cacciabue and I.A. Papazoglou. Berlin, London: Springer-Verlag.

72. Anderson, D.R., J.C. Helton, H.-N. Jow, M.G. Marietta, M.S.Y. Chu, L.E. Shephard, and G. Basabilvazo. 1997. "Conceptual and Computational Structure of the 1996 Performance Assessment for the Waste Isolation Pilot Plant," Advances in Safety and Reliability, Proceedings of the ESREL'97 International Conference on Safety and Reliability: Vol. 1. Ed. C.G. Soares. New York: Pergamon. 515-524.

73. Helton, J.C. 1996. "Computational Structure of a Performance Assessment Involving Stochastic and Subjective Uncertainty," Proceedings of the 1996 Winter Simulation Conference. Eds. J.M. Charnes, D.J. Morrice, D.T. Brunner, and J.J. Swain. Piscataway, NJ: Institute of Electrical and Electronics Engineers. 239-247.

74. Neill, R.H., L. Chaturvedi, D. Rucker, M. Silva, B.A. Walker, J.K. Channell, and T.M. Clemo, Evaluation of the WIPP Project's Compliance with the EPA Radiation Protection Standards for Disposal of Transuranic Waste, EEG-68; DOE/AL/58309-68, Environmental Evaluation Group, Albuquerque, NM, 1998.

75. Rucker, D.F., Sensitivity Analysis of Performance Parameters Used in Modeling the WIPP, EEG-69; DOE/AL/58309-69, Environmental Evaluation Group, Albuquerque, NM, 1998.

76. Silva, M.K., L. Chaturvedi, and D.F. Rucker. 1999. "Resolution of the Long-Term Performance Issues of the Waste Isolation Pilot Plant," Risk Analysis. Vol. 19, no. 5, pp. 1003-1016. 
77. Wilson, C., D. Porter, J. Gibbons, E. Oswald, G. Sjoblom, and F. Caporuscio. 1996-1997. Final Waste Isolation Pilot Plant Conceptual Models Peer Review Report (July 1996, Sandia WIPP Central Files WPO \#41805). Waste Isolation Pilot Plant Conceptual Models Supplementary Peer Review Report (December 1996, Sandia WIPP Central Files WPO \#43153). Waste Isolation Pilot Plant Second Supplementary Peer Review Report (January 1997, Sandia WIPP Central Files WPO \#44536). Carlsbad, NM: U.S. Department of Energy, Carlsbad Area Office, Office of Regulatory Compliance.

78. International Review Group, International Peer Review of the 1996 Performance Assessment of the U.S. Waste Isolation Pilot Plant (WIPP), April 1997. Report of the NEA/IAEA International Review Group, Paris. Sandia WIPP Central Files WPO \#49347, Sandia National Laboratories, Albuquerque, NM, 1997.

79. Hrncir, D.C., E.J. Bonano, J.F. Bresson, and P.J. Robinson. 1996-1997. Waste Isolation Pilot Plant Waste Characterization Analysis Peer Review Report (July 1996, unpublished report included in the CCA as Appendix PEER, Section PEER.3.2), Waste Isolation Pilot Plant Supplementary Waste Characterization Analysis Peer Review Report (EPA Air Docket A-93-02). Carlsbad, NM: U.S. Department of Energy, Carlsbad Area Office.

80. Bhada, R.K., C.T. Aimone-Martin, A. Duran, D.J. Kuhns, C.R. Lewis, J.D. Navratil, J. Rostami, D.M. Smith, and K.K. Wahi. 1996. Waste Isolation Pilot Plant Engineered Alternatives Cost/Benefit Study Peer Review Report. (July 1996, unpublished report included in the CCA as Appendix PEER, Section PEER.4.2). Carlsbad, NM: U.S. Department of Energy, Carlsbad Area Office.

81. Ross-Brown, D., B. Gibbons, D. Porter, and J. Schaltz. 1996-1997. Waste Isolation Pilot Plant Engineered Systems Data Qualification Peer Review Report (July 1996, unpublished report included in the CCA as Appendix PEER, Section PEER.5.2). Waste Isolation Pilot Plant Supplementary Engineered Systems Data Qualification Peer Review Report (December 1996, Item II-G-13). Carlsbad, NM: U.S. Department of Energy, Carlsbad Area Office.

82. Hrncir, D.C. and R.D. Knecht. 1996. Waste Isolation Pilot Plant Waste Form and Disposal Room Data Qualification Peer Review Report (unpublished report included in the CCA as Appendix PEER, Section PEER.6.2). Carlsbad, NM: U.S. Department of Energy, Carlsbad Area Office.

83. Dunn, D.E., F. Caporuscio, P.L. Cloke, D.A. Sommers, C. Wilson, and C.-M. Zhang. 1996. Waste Isolation Pilot Plant Natural Barriers Data Qualification Peer Review Report (August 1996, unpublished report included in the CCA as Appendix PEER, Section PEER.7.2). Carlsbad, NM: U.S. Department of Energy, Carlsbad Area Office.

84. MacKinnon, B.., \& Freeze, G., 1997, Summary of EPA-Mandated Performance Assessment Verification Test (Replicate 1) and Comparison with the Compliance Certification Application Calculations. Technical Data Package. Albuquerque, NM: Sandia National Laboratories. Sandia WIPP Central Files WPO \# 46674.

85. Hansen, F.D., M.K. Knowles, T.W. Thompson, M. Gross, J.D. McLennan, and J.F. Schatz. 1997. Description and Evaluation of a Mechanistically Based Conceptual Model for Spall. SAND97-1369. Albuquerque, NM: Sandia National Laboratories.

86. Public Law 94-580. Resource Conservation and Recovery Act of 1976. (90 Stat 2795; 42 U.S.C. 6901 et seq.). 
87. New Mexico Environmental Department. 1999. Hazardous Waste Facility Permit Issued to Waste Isolation Pilot Plant: EPA No. NM4890139088. Vols. 1-4. Santa Fe: New Mexico Environmental Department.

88. Paté-Cornell, M.E. 1999. "Conditional Uncertainty Analysis and Implications for Decision Making: The Case of WIPP," Risk Analysis. Vol. 19, no. 5, pp. 1003-1016.

89. Kaplan, S. and B.J. Garrick. 1981. "On the Quantitative Definition of Risk," Risk Analysis. Vol. 1, no. 1, pp. 11-27.

90. Helton, J.C. 1994. "Treatment of Uncertainty in Performance Assessments for Complex Systems," Risk Analysis. Vol. 14, no. 4, pp. 483-511.

91. Hoffman, F.O. and J.S. Hammonds. 1994. "Propagation of Uncertainty in Risk Assessments: The Need to Distinguish Between Uncertainty Due to Lack of Knowledge and Uncertainty Due to Variability," Risk Analysis. Vol. 14, no. 5, pp. 707-712.

92. Draper, D. 1995. "Assessment and Propagation of Model Uncertainty," Journal of the Royal Statistical Society Series B. Vol. 57, pp. 45-97.

93. Paté-Cornell, M.E. 1996. "Uncertainties in Risk Analysis: Six Levels of Treatment,". Reliability Engineering and System Safety. Vol. 54, no. 2-3, pp. 95-111.

94. Helton, J.C. 1997. "Uncertainty and Sensitivity Analysis in the Presence of Stochastic and Subjective Uncertainty," Journal of Statistical Computation and Simulation. Vol. 57, no. 1-4, pp. 3-76.

95. Budnitz, R.J., G. Apostolakis, D.M. Boore, L.S. Cluff, K.J. Coppersmith, C.A. Cornell, and P.A. Morris. 1998. "Use of Technical Expert Panels: Applications to Probabilistic Seismic Hazard Analysis," Risk Analysis. Vol. 18, no. 4, pp. 463-469.

96. Thorne, M.C. 1993. "The Use of Expert Opinion in Formulating Conceptual Models of Underground Disposal Systems and the Treatment of Associated Bias," Reliability Engineering and System Safety. Vol. 42 , no. $2-3$, pp. $161-180$.

97. Chhibber, S., G. Apostolakis, and D. Okrent. 1992. "A Taxonomy of Issues Related to the Use of Expert Judgments in Probabilistic Safety Studies," Reliability Engineering and System Safety. Vol. 38, no. 1-2, pp. $27-45$.

98. Bonano, E.J. and G.E. Apostolakis. 1991. "Theoretical Foundations and Practical Issues for Using Expert Judgments in Uncertainty Analysis of High-Level Radioactive Waste Disposal," Radioactive Waste Management and the Nuclear Fuel Cycle. Vol. 16, pp. 137-159.

99. Cooke, R.M. 1991. Experts in Uncertainty, Opinion and Subjective Probability in Science. New York, NY: Oxford University Press.

100. Keeney, R.L. and D. von Winterfeldt, Eliciting Probabilities from Experts in Complex Technical Problems, IEEE Transactions on Engineering Management, 38 (3), 191-201, 1991. 
101. Meyer, M.A. and J.M. Booker. 1991. Eliciting and Analyzing Expert Judgment: A Practical Guide. New York, NY: Academic Press.

102. Hora, S.C. and R.L. Iman, Expert Opinion in Risk Analysis: The NUREG-1150 Methodology, Nuclear Science and Engineering, 102 (4), 323-331, 1989.

103. Mosleh, A., V.M. Bier, and G. Apostolakis, A Critique of Current Practice for the Use of Expert Opinion in Probabilistic Risk Assessment, Reliability Engineering and System Safety, 20 (1), 633-685, 1988.

104. Sanchez, L.C., J. Liscum-Powell, J.S. Rath, and H.R. Trellue. 1997. WIPP PA Analysis Report for EPAUNI: Estimating Probability Distribution of EPA Unit Loading in the WIPP Repository for Performance Assessment Calculations, Version 1.01. Albuquerque, NM: Sandia National Laboratories. Sandia WIPP Central Files WPO \# 43843.

105. Bean, J.E., M.E. Lord, D.A. McArthur, R.J. MacKinnon, J.D. Miller, and J.D. Schreiber, Analysis Package for the Salado Flow Calculations (Task 1) of the Performance Assessment Analysis Supporting the Compliance Certification Application, Albuquerque, NM: Sandia National Laboratories. Sandia WIPP Central Files WPO \# 40514, 1996.

106. Stoelzel, D.M. and D.G. O'Brien. 1996. Analysis Package for the BRAGFLO Direct Release Calculations (Task 4) of the Performance Assessment Analyses Supporting the Compliance Certification Application, Albuquerque, NM: Sandia National Laboratories. Sandia WIPP Central Files WPO \# 40520.

107. Berglund, J.W. 1996. Analysis Package for the Cuttings and Spalling Calculations (Tasks 5 and 6) of the Performance Assessment Analyses Supporting the Compliance Certification Application, Albuquerque, NM: Sandia National Laboratories. Sandia WIPP Central Files WPO \# 40521.

108. LaVenue, A.M. 1996. Analysis of the Generation of Transmissivity Fields for the Culebra Dolomite, Albuquerque, NM: Sandia National Laboratories. Sandia WIPP Central Files WPO \# 40517.

109. Stockman, C., A. Shinta, and J.W. Garner. 1996. Analysis Package for the Salado Transport Calculations (Task 2) of the Performance Assessment Analysis Supporting the Compliance Certification Application, Albuquerque, NM: Sandia National Laboratories. Sandia WIPP Central Files WPO \#40515.

110. Ramsey, J.L., M.G. Wallace, and H.-N. Jow. 1996. Analysis Package for the Culebra Flow and Transport Calculations (Task 3) of the Performance Assessment Analyses Supporting the Compliance Certification Application, Albuquerque, NM: Sandia National Laboratories. Sandia WIPP Central Files WPO \# 40516.

111. Smith, L.N., J.D. Johnson, and J.C. Helton. 1996. Analysis Package for the CCDF Construction (Task 7) of the Performance Assessment AnalysesSupporting the Compliance Certification Application, Albuquerque, NM: Sandia National Laboratories. Sandia WIPP Central Files WPO \# 40524.

112. Howarth, S.M. and T. Christian-Frear. 1997. Porosity, Single-Phase Permeability, and Capillary Pressure Data from Preliminary Laboratory Experiments on Selected Samples from Marker Bed 139 at the Waste Isolation Pilot Plant. SAND94-0472/1/2/3. Albuquerque, NM: Sandia National Laboratories. 
113. Powers, D.W., J.M. Sigda, and R.M. Holt. 1996. "Probability of Intercepting a Pressurized Brine Reservoir Under the WIPP," Records package. Albuquerque, NM: Sandia National Laboratories. Sandia WIPP Central Files WPO \# 40199.

114. Meigs, L. 1996. "Non-Salado: Culebra Advective Porosity," Records package. Albuquerque, NM: Sandia National Laboratories. Sandia WIPP Central Files WPO \# 37227.

115. Christian-Frear, T.L. 1996. "Salado Halite Rock Compressibility from Room Q Analysis," Records packages. Albuquerque, NM: Sandia National Laboratories. Sandia WIPP Central Files WPO \# 30598, WPO \# 31220.

116. Domski, P. 1996. "Salado: Halite Permeability," Records package. Albuquerque, NM: Sandia National Laboratories. Sandia WIPP Central Files WPO \# 31218.

117. Siegel, M.D. 1996. "Solubility Parameters for Actinide Source Term Look-Up Tables," Records package. Albuquerque, NM: Sandia National Laboratories. Sandia WIPP Central Files WPO \# 35835.

118. WIPP PA (Performance Assessment), BRAGFLO, Version 4.00, User's Manual, Sandia WIPP Central Files WPO \#30703, Sandia National Laboratories, Albuquerque, NM, 1996.

119. Stone, C.M. 1997. SANTOS - A Two-Dimensional Finite Element Program for the Quasistatic, Large Deformation, Inelastic Response of Solids. SAND90-0543. Albuquerque, NM: Sandia National Laboratories.

120. WIPP PA (Performance Assessment), 1996. NUTS, Version 2.02, Version 5/23/96, User's Manual. Albuquerque, NM: Sandia National Laboratories. Sandia WIPP Central Files WPO \#37927.

121. WIPP PA (Performance Assessment), 1996. PANEL, Version 3.60, User's Manual. Albuquerque, NM: Sandia National Laboratories. Sandia WIPP Central Files WPO \# 37361.

122. Roache, P.J., R.L. Blaine, and B.L. Baker. 1996. SECOFL2D User's Manual, Version 3.03. Albuquerque, NM: Sandia National Laboratories. Sandia WIPP Central Files WPO \# 37271.

123. WIPP PA (Performance Assessment). 1997. SECOTP2D, Version 1.41, User's Manual, Albuquerque, NM: Sandia National Laboratories. Sandia WIPP Central Files WPO \# 45734.

124. Johnson, J.D. 1997. CCDFGF, Version 4.00, User's Manual. Albuquerque, NM: Sandia National Laboratories. Sandia WIPP Central Files WPO \# 47364.

125. Smith, L.N., LHS, Version 2.4.1 User's Manual, Sandia WIPP Central Files WPO \# 30732, Sandia National Laboratories, Albuquerque, NM, 1996.

126. WIPP PA (Performance Assessment), STEPWISE, Version 2.20, User's Manual, [Document Version 1], Sandia WIPP Central Files WPO \# 27768, Sandia National Laboratories, Albuquerque, NM, 1995.

127. WIPP PA (Performance Assessment). 1995. PCCSRC, Version 2.21, User's Manual [Document Version 1.0]. Albuquerque, NM: Sandia National Laboratories. Sandia WIPP Central Files WPO \# 27773. 
128. Ewing, R.C. 1999. "Less Geology in the Geological Disposal of Nuclear Waste," Science. Vol. 286, pp. 415-416.

129. North, D.W. 1999. "A Perspective on Nuclear Waste," Risk Analysis. Vol. 19, no. 4, pp. 751-758.

130. Thompson, B.G.J. 1999. "The Role of Performance Assessment in the Regulation of Underground Disposal of Radioactive Wastes: An International Perspective," Risk Analysis. Vol. 19, no. 5, pp. 809-846.

131. Okrent, D. 1999. "On Intergenerational Equity and Its Clash with Intragenerational Equity and on the Need for Policies to Guide the Regulation of Disposal of Wastes and Other Activities Posing Very LongTerm Risks," Risk Analysis. Vol. 19, no. 5, pp. 877-901.

132. Ewing, R.C., M.S. Tierney, L.K. Konikow, and R.P. Rechard. 1999. "Performance Aassessments for Nuclear Waste Repositories: A Dialogue on Their Values and Limitations," Risk Analysis. Vol. 19, no. 5, pp. 933-958.

133. Ahearne, J.F. 1997. "Radioactive Waste: The Size of the Problem," Physics Today. Vol. 50, no. 6, pp. 24-29.

134. Crowley, K.D. 1997. "Nuclear Waste Disposal: The Technical Challenges," Physics Today. Vol. 50, no. 6, pp. 32-39.

135. Kastenburg, W.E. and L.J. Gratton. 1997. "Hazards of Managing and Disposing of Nuclear Waste," Physics Today. Vol. 50, no. 6, pp. 41-46.

136. North, D.W. 1997. "Unresolved Problems of Radioactive Waste: Motivation for a New Paradigm," Physics Today. Vol. 50, no. 6, pp. 48-54.

137. McCombie, C. 1997. "Nuclear Waste Management Worldwide," Physics Today. Vol. 50, no. 6, pp. 5662.

138. Flynn, J., R.E. Kasperson, H. Kunreuther, and P. Slovic. 1997. "Overcoming Tunnel Vision: Redirecting the U.S. High-Level Nuclear Waste Program," Environment. Vol. 39, no. 3, pp. 6-11, 25-30.

139. Carter, L.J. and T.H. Pigford. 1999. "The World's Growing Inventory of Civil Spent Fuel," Arms Control Today. Vol. 29, no. 1, pp. 8-14. 
Figure Captions

Fig. 1. Distribution of CCDFs for total normalized release to accessible environment over $10,000 \mathrm{yr}$ due to cuttings and cavings, spallings and direct brine release: (1a) CCDFs for replicate $\mathrm{R} 1$, and (1b) mean and percentile curves obtained by pooling replicates R1, R2 and R3.

Fig. 2. Outcome of replicated sampling for distribution of CCDFs for total normalized release to the accessible environment over 10,000 yr due to cuttings and cavings, spallings and direct brine release: (2a) mean and percentile curves for individual replicates, and ( $2 b$ ) confidence intervals (CIs) on mean curve obtained from the three replicates.

Fig. 3. Distribution of expected values for total normalized release due to (i) cuttings and cavings (CUTREL), (ii) spallings (SPLREL), (iii) direct brine release (DBREL), (iv) groundwater transport to Culebra (CULREL), and (v) cuttings and cavings, spallings and direct brine release combined (TOTREL).

Fig. 4. Scatterplots for expected normalized releases associated with individual CCDFs for total release due to cuttings and cavings, spallings and direct brine release versus WMICDFLG, WTAUFAIL, WPRTDIAM and BHPRM.

Fig. 5. Sensitivity analysis based on PRCCs for CCDFs for total normalized release to the accessible environment due to cuttings and cavings, spallings and direct brine release. 

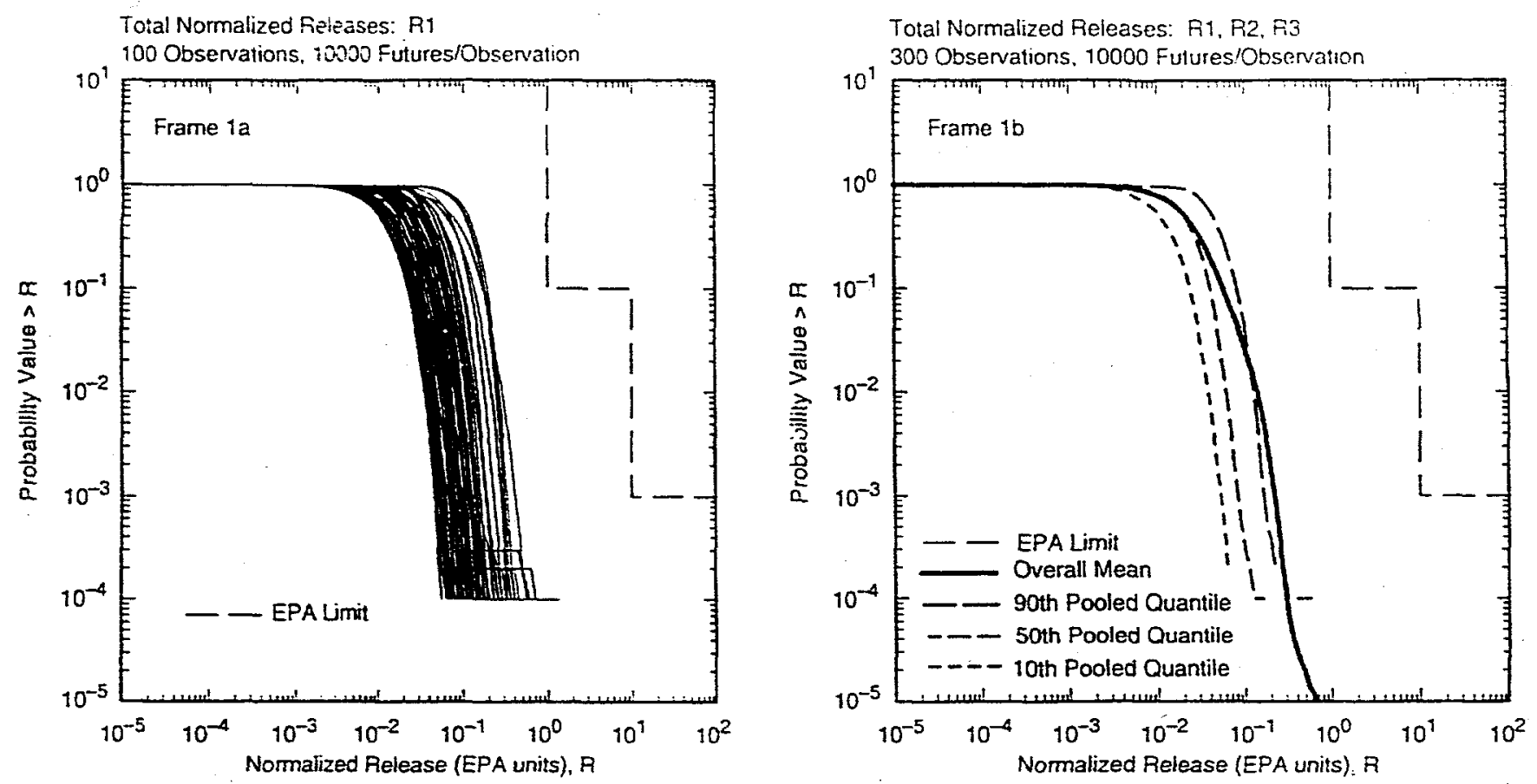

TRI-6342-4999-1

Fig. 1. Distribution of CCDFs for total normalized release to accessible environment over $10,000 \mathrm{yr}$ due to cuttings and cavings, spallings and direct brine release: (1a) CCDFs for replicate R1, and (1b) mean and percentile curves obtained by pooling replicates $\mathrm{R} 1, \mathrm{R} 2$ and $\mathrm{R} 3$.
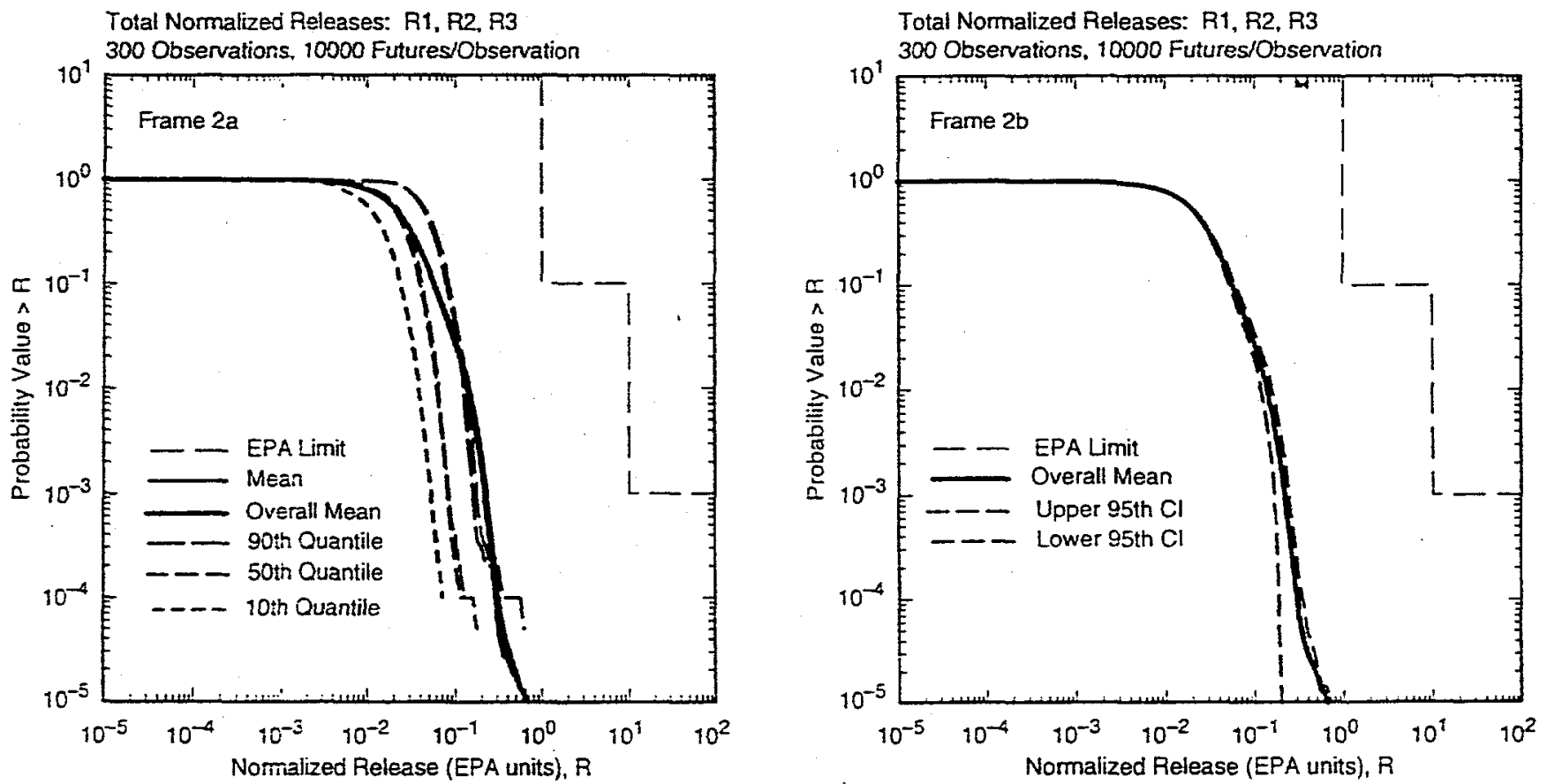

TAI-6342-5000-1

Fig. 2. Outcome of replicated sampling for distribution of CCDFs for total normalized release to the accessible environment over 10,000 yr due to cuttings and cavings, spallings and direct brine release: (2a) mean and percentile curves for individual replicates, and (2b) confidence intervals (CIs) on mean curve obtained from the three replicates. 


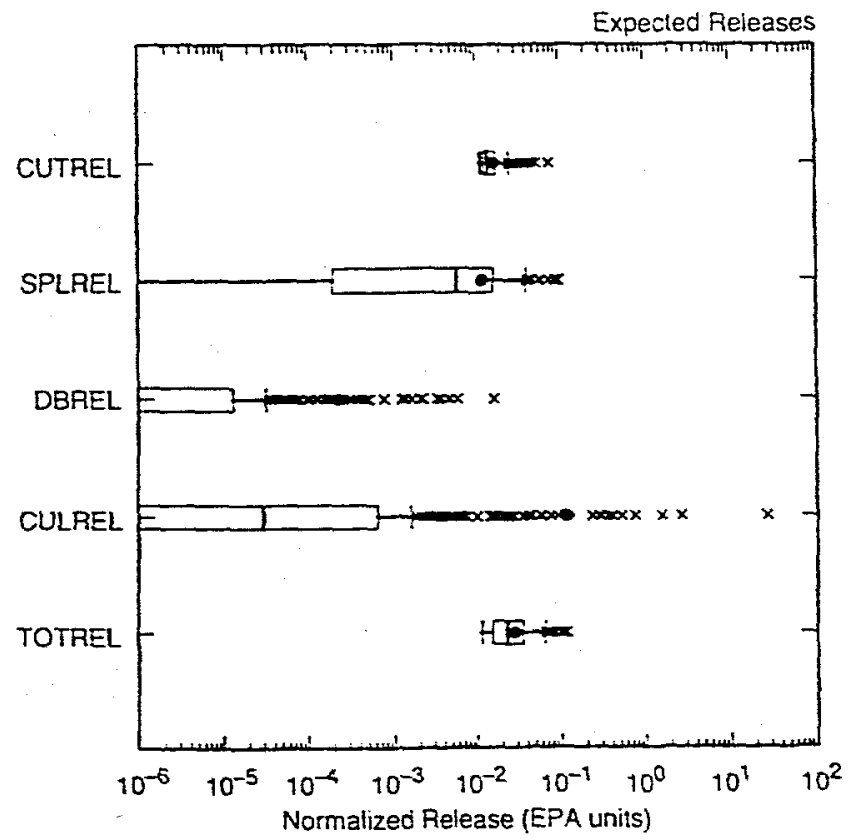

TR1-5342-5179-0

Fig. 3. Distribution of expected values for total normalized release due to (i) cuttings and cavings (CUTREL), (ii) spallings (SPLREL), (iii) direct brine release (DBREL), (iv) groundwater transport to Culebra (CULREL), and ( $v$ ) cuttings and cavings, spallings and direct brine release combined (TOTREL). 

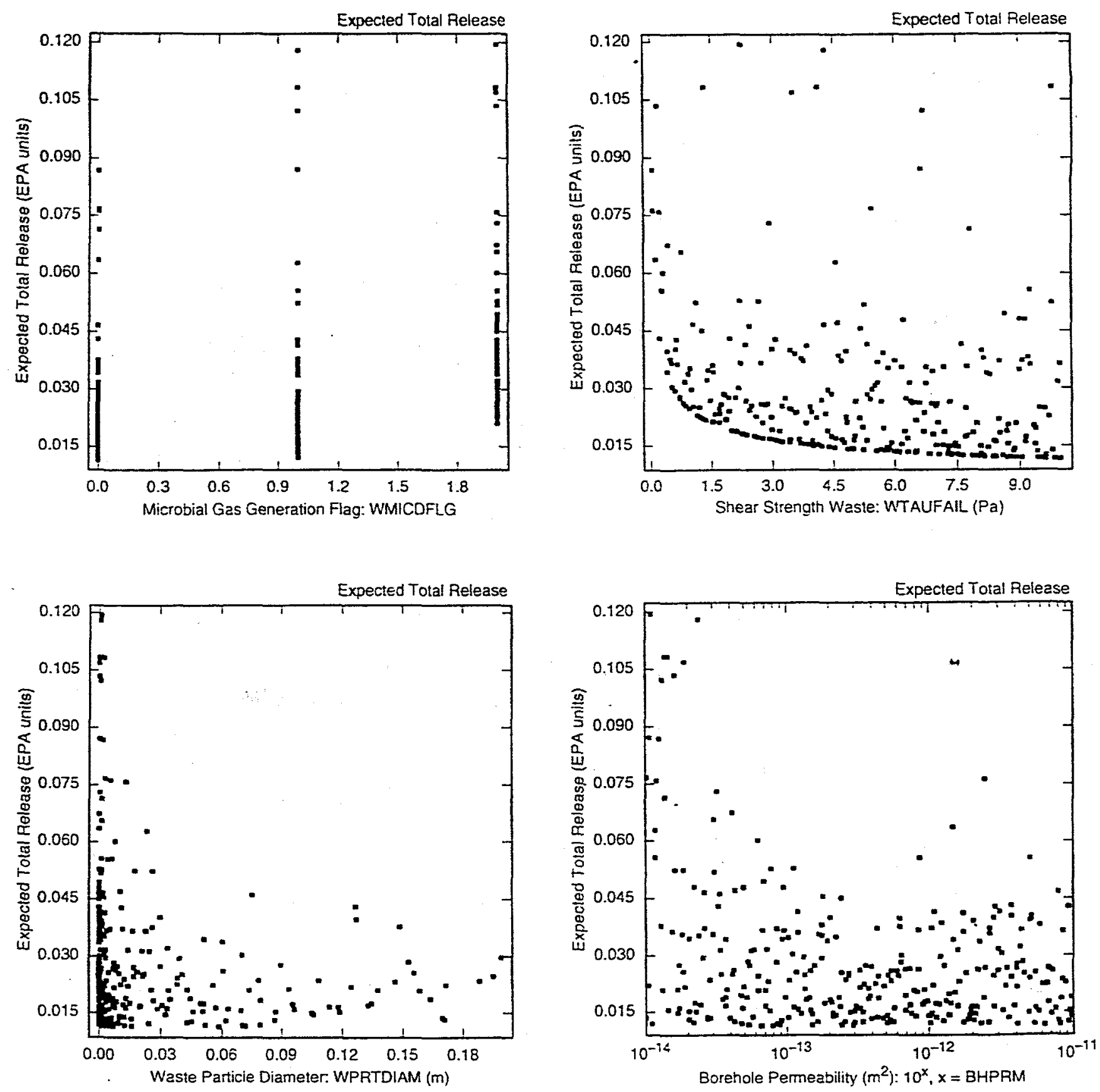

TRI-E342.5180-0

Fig. 4. Scatterplots for expected normalized releases associated with individual CCDFs for total release due to cuttings and cavings, spallings and direct brine release versus WMICDFLG, WTAUFAIL, WPRTDIAM and BHPRM. 
Total Normalized Releases: R1, R2, R3

300 Observations, 10000 Futures/Observation

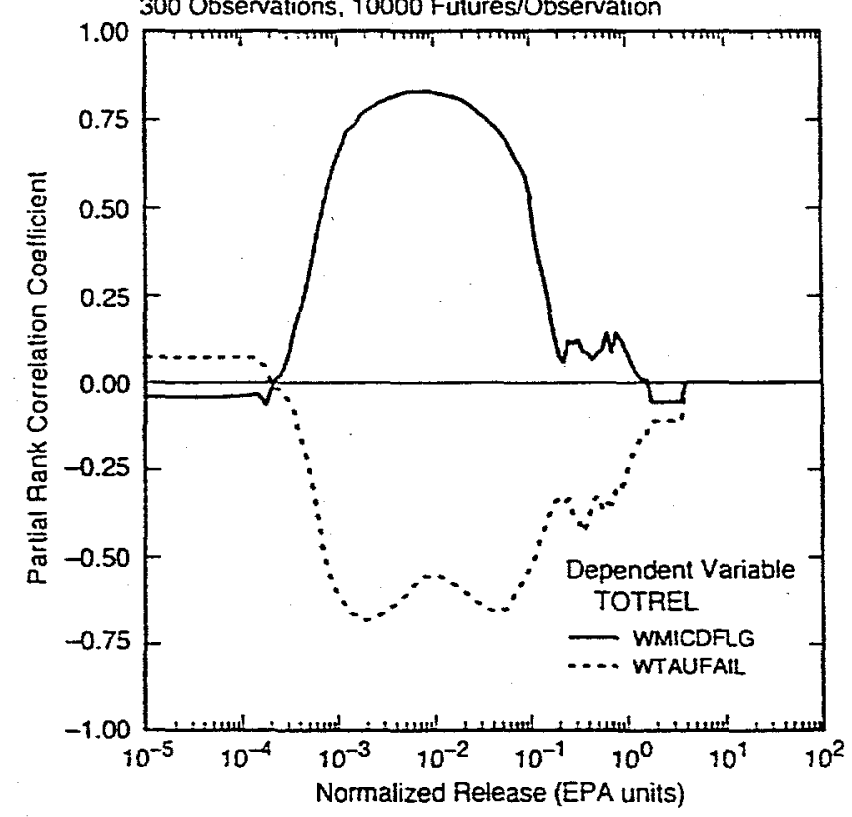

TRI-63<2.5189-0

Fig. 5. Sensitivity analysis based on PRCCs for CCDFs for total normalized release to the accessible environment due to cuttings and cavings, spallings and direct brine release. 
Table 1. Stepwise Regression Analysis with Rank-Transformed Data for Expected Normalized Release Associated with Individual CCDFs for Total Release Due to Cuttings and Cavings, Spallings and Direct Brine Release

\begin{tabular}{|c|l|c|c|}
\cline { 2 - 4 } \multicolumn{1}{c|}{} & \multicolumn{3}{c|}{ Expected Normalized Release } \\
\hline Step $^{\mathrm{a}}$ & \multicolumn{1}{|c|}{ Variable $^{\mathrm{b}}$} & SRRC $^{\mathrm{c}}$ & $R^{2 \mathrm{~d}}$ \\
\hline 1 & WMICDFLG & 0.60 & 0.40 \\
2 & WTAUFAIL & -0.39 & 0.55 \\
3 & WGRCOR & 0.21 & 0.59 \\
4 & WPRTDIAM & -0.19 & 0.63 \\
5 & HALPOR & 0.17 & 0.65 \\
6 & BHPRM & -0.17 & 0.68 \\
7 & HALPRM & 0.16 & 0.71 \\
8 & WASTWICK & 0.11 & 0.72 \\
9 & ANHPRM & 0.09 & 0.73 \\
\hline
\end{tabular}

a Steps in stepwise regression analysis.

b Variables listed in order of selection in regression analysis with $A N H C O M P$ and $H A L C O M P$ excluded from entry into regression model.

c Standardized rank regression coefficients in final regression model.

${ }^{d}$ Cumulative $R^{2}$ value with entry of each variable into regression model. 